\title{
Pricing Extreme Attributes in Commercial Real Estate: The Case of Hotel Transactions
}

\section{Prashant Das • Patrick Smith • Paul Gallimore}

\begin{abstract}
We show that conventional hedonic models for commercial real estate prices ignore the utility investors derive from a building's extreme attributes. Analyzing geo-enriched data on nearly 4,800 hotel transactions in the United States, we find that the relative positioning of an asset's attributes - particularly at the extremes - has a significant impact on transaction prices. We also detect separating equilibria for extreme attributes across the premium and discount hotel segments. Extreme attributes "stand out" and are value enhancing in premium hotel segments. In contrast, extreme attributes are value diminishing in the discount hotel segment. The relative degree to which the asset's attributes are extreme is important. Being a locally largest asset has a negative effect on price, however the negative effect is more than offset if the hotel is among the largest hotels nationally. The results suggest that locally extreme assets, unless also nationally extreme, are considered atypical and trade at a discount.
\end{abstract}

JEL Classifications: A14, G12, M31, R32

Keywords Hedonic models · Price premium • Veblen effect . GIS · Commercial Real Estate · Hotels

An earlier version of the paper received the best paper award in real estate category at the Asian Real Estate Society Conference, Bangalore- 2016. This manuscript has benefitted greatly from the anonymous referees of the journal. The authors are thankful to the following individuals for their contributions to this study: Duane Vinson and Steve Hood (STR Global), Jamie Alcock, Gabrielle Bodenmann, Yong Chen, Steffen Raub, Sean Way, Karthik Namasevayam, Emmanuel Jurczenko, Ramya Aroul, Jonathan Humphries, Frederick Delley, Marc Steirand, Oliver Judge, Adnan Shamim, and many others.

P. Das ( $\square)$

Asstt. Professor of Real Estate Finance, Ecole hôtelière de Lausanne, HES.SO // University of Applied Sciences Western Switzerland, route de Cojonnex 18, 1000 Lausanne

e-mail: prashant.das@ehl.ch

P. Smith

Asstt. Professor of Finance, Fowler College of Business Administration, San Diego State University, 5500

Campanile Drive, San Diego, CA 92182-8230

e-mail: patrick.smith@sdsu.edu

P. Gallimore

Visiting Professor of Real Estate at Henley Business School, University of Reading, RG6 6UD, United Kingdom, United Kingdom

e-mail: p.gallimore@henley.reading.ac.uk 


\section{Introduction}

A well-accepted belief is that commercial real estate investors are willing to overpay for premium assets that "stand out". A behavioral explanation for the phenomenon is that premium assets are conspicuously different and that their purchase advertises the financial strength of the investor. In this study we examine if the assets' conspicuity - and thus investors' interest in the asset - is related to its extreme attributes. Specifically, we examine whether nationally or locally superlative physical attributes (size, height, age) explain a portion of the pricing variation that is often interpreted as the investor overpaying.

Hedonic models explain market equilibrium by estimating the "intrinsic" value of an asset based on its own attributes (Rosen, 1974). Such models often include a comprehensive list of the subject asset's attributes, but typically do not account for the attributes of competing assets. In this study, we argue that relativities between certain attributes of an asset and its competition, both locally and nationally, may independently impact value - especially if the attribute offers the impression of exclusiveness and rarity. When pricing the relativities we recognize that extreme attributes may have contrasting effects across market segments. For example, an extreme attribute may be value enhancing in the premium market segment, but value diminishing in the discount market segment.

Assets in the premium segment are often defined as the top percentile of properties in a given subcategory. Such properties are known for their architecture, historical significance, spectacular design, or some other defining physical characteristic that sets them apart. "Standing out" in the premium segment makes an asset attractive to investors looking to conspicuously do the same ${ }^{1}$. Premium assets' ability to stand out and their inherently limited supply provide an intuitive explanation for why their transaction price often exceeds their underlying intrinsic value. However, standing out can be detrimental in the discount market segment where extreme attributes may render an asset as "atypical." Atypical assets, due to their specificity, have limited demand and hence trade at discounted prices. In this study, we explain the contexts in which an asset's extreme attribute results in a sales price premium or an atypicality discount. ${ }^{2}$

First, using a comprehensive dataset that includes nearly 4,800 asset transactions in the United States from 1991 to 2013 we run baseline hedonic models to confirm the findings of earlier studies. Similar to previous studies, we show that a large part of asset price variation is explained by fundamentals: the asset's physical attributes, location and market cycle. We call it the "baseline model.” In enhanced models we also show the significant association of price with transaction conditions, buyer characteristics, news coverage and location status.

After running the baseline models and reconciling the results from previous studies, we shift our focus to the relative positioning of the asset's attributes. We create several relative and extreme attribute variables and regress them against the price component left unexplained by the baseline models (i.e. the residual). A positive residual signifies a premium market segment whereas a

\footnotetext{
${ }^{1}$ Investors' desire to conspicuously stand out is particularly true in the hotel segment:

(1) https://www.hotel-online.com/Trends/Andersen/Trophy_Investments.html

(2) http://www.wsj.com/articles/SB107706340089632085

(3) http://www.wsj.com/articles/waldorf-astoria-hotel-sale-completed-1423705536 ,

(4) http://www.shanghaidaily.com/supplement/real-estate/Huge-jump-in-trophy-hotels-changing-hands/shdaily.shtml

${ }^{2}$ We provide a comprehensive review of the literature later in the paper in the background section.
} 
negative residual signifies a discount segment. We show that the relative positioning of an asset's attributes - especially at the extremes - has a significant impact on transaction prices. We also find strong evidence of a separating equilibrium across premium and discount market segments with respect to extreme asset attributes. For example, being locally the tallest, nationally the tallest or nationally the oldest is detrimental to assets in the discount market segment; although the same attributes enhance value in the premium market segment. In addition, we find some evidence that extreme attributes create significant externalities for neighboring assets. Oldest and largest assets create positive externalities in the premium segments, but negative or insignificant (respectively) externalities in the discount segments.

\section{Contributions of this study}

We extend the growing literature on conspicuous consumption of residential real estate (such as Lee and Mori 2015; Zahirovich-Herbert and Chatterjee 2011; Heffetz 2011) into the domain of commercial real estate. To our knowledge, this is the first study focusing on investor behavior with respect to conspicuous commercial real estate assets. As consumption and investment are different decisions, theories of consumption may not extend to investment when explaining purchase behavior. Unlike consumers, signaling wealth may not be a legitimate motivation for commercial real estate investors (which are predominantly firms) if they focus only on maximizing their wealth through returns. Yet, there is a pervasive trend of overpaying for certain assets in this real estate sector - which we examine in detail in this study.

The existing literature that examines extreme property attributes typically focuses on a single isolated attribute using data restricted to specific metropolitan areas. Thus, the results of previous studies, which price them individually in isolation, may be biased if the extreme attributes are correlated. In this study, we include multiple attributes to examine their conspicuity. We separately analyze the conspicuity at local level (i.e. neighborhood defined by trade-area) using GIS capabilities as well as at national level. By detecting separating equilibria across premium and discount market segments in pricing the extreme attributes, our study shows the limitations of traditional hedonic models. The traditional hedonic models may be susceptible to omitted variable bias by ignoring the externalities caused by extreme asset attributes. We show how such models can be significantly enhanced by including additional explanatory variables measurable from already available data.

\section{Background and Theory}

\section{Separating Equilibrium}

Beyond the standard utility provided by a purchased good, buyers are sensitive to the symbolism targeted at others. The "Veblen effect" suggests that some buyers like to signal their higher status by conspicuously standing-out and separate the equilibrium by increasing budget towards buying something visibly superior (Heffetz, 2011).

Most existing studies on the purchase of conspicuous goods focus on individual or household consumption. For example, Lee and Mori (2015) shows that metro areas with high conspicuous demand for luxury goods pay significantly higher than intrinsic values for homes to "flaunt their wealth." Such a phenomenon of paying premium prices to buy status through property "names" has also been noted in Zahirovich-Herbert and Chatterjee (2011). 
The phenomenon of conspicuous consumption differentiates itself from investing in conspicuous assets. While the purchase of residential real estate is primarily a consumption-related decision, purchasing a commercial real estate asset is mostly an investment decision. Sporadically, a firm may invest in a commercial property (e.g. office, warehouse, etc.) for its own corporate use such that the purchase of a commercial real estate asset is more consumption-related. However, in asset classes such as hotels an investor will not consume the purchased asset; but is intent on maximizing the return by renting it to others. Therefore, conspicuity should be a muted motivation. This is reflected in the literature: much has been documented about consumers' desire to "stand out" (Bagwell and Bernheim, 1996; Corneo and Jeanne, 1997; Ellingsen and Johannesson, 2008) but our knowledge about the financial prudence of investing in conspicuous assets is fragmented despite substantial evidence on the demand for such assets (Ackert and Church 2006; Esrig, Hudgins and Carreta 2011). Some studies even stress negative outcomes of investing in conspicuous assets (Malmendier and Tate 2005; Barr 2010a; Barr 2010b; Bènabou and Tirole 2009; Capozza, Israelsen, and Thomson 2005; Blal and Graf 2013; Ziering and McIntosh 1999) primarily owing to their "atypical” attributes.

Investors' preference for such assets may, however, be rational. For example, studies (Barr, 2010a, 2010b) show that the race for being the tallest building is driven by economic fundamentals. Therefore, conspicuity of a commercial asset may still appeal to prudent investors. We adopt the theoretical framework of conspicuous consumption originally presented by Heffetz (2011) in the context of commercial real estate investment as follows:

Suppose, an asset is listed for price $y$ and investors must raise the same amount of capital to buy the asset. The total asset price (the investor's budget) may be divided into intrinsic utility $(w)$ and conspicuity $(v)$ as follows:

$$
y=v+w
$$

Here, $v=f\left(k_{1}, k_{2} \ldots k_{l}\right)$ where $k$ depicts a set of $l$ conspicuous asset attributes. The utility derived from such an investment is traditionally depicted as:

$$
f(v, w)=\beta_{v} \ln (v)+\beta_{w} \ln (w)
$$

However, if $a(0<a<1)$ equals an investor's sensitivity to the conspicuous status derived from the investment, the utility function is modified as:

$$
U=(1-a) \cdot f(v, w)+a \cdot f(\hat{v}, \widehat{w})
$$

Here $\hat{v}$ and $\widehat{w}$ denote externally perceived belief regarding $v$ and $w$. Heffetz (2011) shows that if the conspicuity-consciousness exists, $($ i.e. $\neq 0$ ), then $v$ 's elasticity can be shown as:

$$
e_{v} \equiv\left(\frac{d v}{v} / \frac{d y}{y}\right)>1
$$

This inequality implies a separating equilibrium: at lower asset prices investors spend minimally on $v$. However, as $y$ rises, investors spend an increasing share of their budget on $v$. In this study, we break up the conspicuity of an asset into marginal effects of $k$ attributes such that $e_{v_{k}} \equiv\left(\frac{\partial v_{k}}{v_{k}} / \frac{\partial y}{y}\right)$. Premium investors are sensitive to attribute $k$ if $e_{v_{k}} \neq 1$ or that $\frac{\partial y}{\partial k}$ changes across quantiles of $y$. 
The phenomenon of separating equilibrium is associated with sellers playing with signals sent to buyers. As real estate assets are built with an assumption of highest and best use, the baseline value (NPV) at the development stage is assumed to surpass the cost of development. At the outset, extreme size or height "advertise” the conspicuous attributes. However, advertisement is associated with additional set up and ongoing costs. Depending on how the market evolves in future, assets are known to gain or lose value in real terms. Traditional hedonic models enable an investor to estimate the baseline value. Contingent on the market conditions, if an asset is selling above (below) the baseline, it falls in the "premium" ("discount”) segment. From the principle of "separating equilibrium”, investors infer different quality signals from the conspicuous attributes across the two segments.

From the Game Theory principles, for consumer goods or services in lower quality segments a seller can ensure profitability by eliminating the cost of advertisement (Harrington, Jr, 2009). However, sellers of commercial real estate cannot dynamically get rid of such costs of "advertisement" due to the fixity of extreme physical attributes. As the value discount is fairly visible to the buyers from baseline hedonic models, they further discount the extreme attributes to compensate for the unavoidable future costs associated with the atypicality of the asset. As a result, the pricing in the lower quality ("discount") segments is further "hurt" due to these attributes (Campbell, 2014). This implies that in real estate assets the separating equilibrium should be valid both in the discount and premium segments.

Therefore, we further generalize Heffetz's (2011) framework: separated equilibria will develop as long as $e_{v_{k}}$ varies across y. By inference, if $\left.\frac{\partial y}{\partial k}\right|_{\tilde{y}}>\left.\left.\frac{\partial y}{\partial k}\right|_{y} A N D \frac{\partial y}{\partial k}\right|_{y}>0$; where $\tilde{y}$ and $\underbrace{}_{w}$ imply overpriced ("premium”) and underpriced quantiles of $y$, the attribute $k$ may be considered, a “premium enhancing” attribute. Similarly, if $\left.\frac{\partial y}{\partial k}\right|_{\hat{y}}<\left.\left.\frac{\partial y}{\partial k}\right|_{y} A N D \frac{\partial y}{\partial k}\right|_{y}<0$, the attribute $k$ still separates the equilibrium in the discount segment, although, in this case, as a "value diminishing" attribute. In this study, we focus on the conspicuity of asset attributes $(k)$ stemming from their extremities as discussed below.

\section{Externality of Conspicuous Assets}

The above mentioned framework addresses an asset's attribute relative to other assets. However, the presence of neighboring assets with extreme attributes may create externalities, positive or negative. For example, Leguizamon (2010) shows that being close to larger homes leads to an "envy effect" which negatively impacts home prices. On the other hand, "snob" investors in $v$ may intend to send a message that their rank is better than a certain proportion of the population and for such buyers, the utility of purchasing is "enhanced by its rarity" (Corneo and Jeanne 1997).

\section{Sources of Conspicuity}

\section{Extreme Physical Attributes}

Among others explanations, determinants of commercial capitalization rates may offer cues to identifying asset attributes to which premium investors may be sensitive. Earlier studies note that beyond market fundamentals, commercial cap rates in general (Ghysels, Plazzi and Valkanov 2007) and hotel cap rates in particular (Das, 2015) are prone to socio-political differences which 
are not directly associated with risk-reward fundamentals. Other studies such as Lockwood and Rutherford (1996), Mcdonald and Dermisi (2008), Peng (2013), and McGrath (2013) have shown an association between tangible attributes and cap rates: size (-ve), age (+ve), higher classification (-ve), access to amenities (-ve) and eco-labels (e.g. LEED or Energy Star).

Some studies suggest that large real estate assets perform better in a portfolio context (Pai and Geltner 2007; Plazzi , Torous and Valkanov 2011; Esrig et al. 2011) while Kallberg, Liu, and Greig (1996) and Ziering and McIntosh (1999) report the opposite. Esrig et al. (2011) provide an explanation for the better performance of large assets: when rents fall, the bad impacts of the down market are offset by improved occupancy rate (as lower quality tenants move up). Several motivations for tall buildings are proposed in the literature such as ego or status (Barr 2010a; Barr 2010b), symbolism (Helsley and Strange, 2008), and internal synergy (Titman and Twite 2013). These motivations broadly suggest a price premium on tall buildings. However, Helsley and Strange (2008) argue that building the tallest building in a market is also at a risk of poor economics which may dissipate the premium created by the "premium" status.

High-status localities

Gat (1998) shows that prestige-conscious buyers of commercial real estate are more sensitive to postal-address than to building height or size. Owners of commercial real estate are cognizant that certain localities bring in higher prestige (Brennan, Cannaday, \& Colwell, 1984). Gat (1998) reports that access to urban foci (CBD) is priced into commercial real estate assets. If CBDs and top tier cities are preferred, assets in these locations should enjoy price premiums. However, there are some downsides to such locations. For example, CBDs are more exposed to terrorism threats (Abadie and Dermisi, 2008) implying that the additional cost of security should be capitalized into initial price discounts. Besides, Lizieri and Pain (2013) suggest that lower-tier cities offer superior diversification benefits and, by implication, should enjoy premiums.

In addition to $\mathrm{CBD}$, assets that fall into state-capital metropolitan areas, high population growth areas or affluent localities may enjoy premium prices. ESRI's tapestry segmentation ${ }^{3}$ refers to clusters of households based on socio-economic and demographic attributes. Data are collected from a variety of sources including the US Census and several private consumer data companies. Based on robust clustering techniques at block-group level, each tapestry is identified with typical household attributes and preferences. For example, the typical household of tapestry segment 1A ("Top Tier") includes the following household attributes and preferences: "An affluent white married couple ... having college degrees... average age is 46 years; earns $\$ 175 \mathrm{k}$...owned singlefamily home... owns lavish vacation family, ... buying at high-end retailers, ... uses fully equipped luxury cars...”.

\section{News Coverage}

Studies such as Ackert and Church (2006) and Billett et al. (2011) show investors' sensitivity towards media coverage. Our survey of available data suggests that most news coverage enjoyed by hotels is due to them hosting notable events. Therefore, persistent news coverage is associated with extremely top-class assets: luxury and upper-upscale assets. Lower class assets may only be sporadically covered in news.

\footnotetext{
${ }^{3}$ See Appendix 1 for Tapestry segmentation details.
} 


\section{Data}

Detailed information on asset transactions such as price, date, type (standalone asset sales versus portfolio sale or multi-property sale), buyer intent (investment versus self-use), and broad level physical attributes of the property are extracted from Costar's COMPS database. We exclude transactions that were reported as non-arm's length. Although it offers a rich dataset, Costar does not provide every hotel attribute known to affect pricing. To enrich the empirical dataset, we match the CoStar data with data provided by Smith Travel Research (STR). The STR data includes nearly 100 attributes for approximately 55,000 hotels in the United States. The attributes include the physical characteristics of the hotel (number of hotel rooms, number of floors, amenities), operational attributes (brand affiliation, asset category), and geographic attributes (coordinates, market, submarket, etc.). Some critical asset attributes were missing from both STR and CoStar databases leading to some transactions being dropped. Several transactions are also excluded if there was no match between the two sources. The matched dataset used in the empirical analysis includes 4,784 hotel transactions.

We further use the STR dataset to create additional variables for the empirical analysis. This ensures that the extreme attributes we identify are relative to the entire census of hotels in the United States. For each hotel transaction, we record if any of its attributes $(k=)$ - age, number of rooms and number of floors - are among the top 99\% nationally and accordingly identify them as nationally oldest, largest or tallest respectively. Similar variables are created on the local level as well. We describe them in the GIS Enhancements section below.

Table 1 provides a list of variables included in the empirical analysis. The table also include a definition of the variable, its source, and descriptive statistics. We found some discrepancies in asset attributes reported across the two sources (CoStar and STR) in variables such as asset starting year and size. In such cases, we apply the STR data. For each transaction, we calculate the asset age based on the transaction date. Several assets changed their brand affiliation after the transaction. STR provides information on a hotel's current and past affiliations. In some instances, the sale date reported by CoStar is earlier than the affiliation date for the current brand reported by STR. According to HVS ${ }^{4}$, a leading hotel consulting firm, the average length of brand contracts exceeds 15 years. Therefore, we select "Ex-Affiliation" as specified by STR for such assets to identify their affiliation at the time of sale, so long as the date difference is within 10 years. Observations with longer differences are excluded from the sample to avoid brand ambiguity.

Buyer Characteristics

A hotel's transaction price may also be influenced by the characteristics and intent of the buyer. For example, an investors' impatience and eagerness to close a deal may lead to premium pricing (Corgel and deRoos 1994; Nesbitt and Phen 1995). By inference, an aggressive buyer may overpay for an asset. There is some inconsistency in how the buyer and seller names are recorded in the CoStar database. Therefore, we manually identify the same buyer specified by differing names as one entity ${ }^{5}$. Also, sister companies were identified as the same buyer ${ }^{6}$.

\footnotetext{
${ }^{4}$ See “2013 UNITED STATES HOTEL FRANCHISE FEE GUIDE” by HVS

${ }^{5}$ E.g. Accor North America Corp versus Accor North America

${ }^{6}$ E.g. Apple REIT companies versus Apple REIT Eight
} 
Table 1 Descriptive Statistics

\begin{tabular}{|c|c|c|c|c|c|c|}
\hline Variable & Definition & Mean & $\begin{array}{r}\text { St. } \\
\text { Dev. }\end{array}$ & Min. & Max. & Source \\
\hline \multicolumn{7}{|l|}{$\begin{array}{l}\text { Transaction } \\
\text { Attributes }\end{array}$} \\
\hline SALEPRICE & Transaction price recorded & $\begin{array}{r}15.3 \\
\mathrm{mi}\end{array}$ & $46.6 \mathrm{mi}$ & $1 \mathrm{mi}$ & $\begin{array}{r}808.8 \\
\mathrm{mi}\end{array}$ & CoStar \\
\hline PORTFOLIO & Dummy for a portfolio sale & 0.102 & & 0 & 1 & CoStar \\
\hline MULTIPROPERTY & Dummy for a multi-property sale & 0.037 & & 0 & 1 & CoStar \\
\hline INVESTMENT & Dummy specifying third-party tenant & 0.901 & & & & CoStar \\
\hline SELFRUN & $\begin{array}{l}\text { Dummy specifying self-run hotel by } \\
\text { the purchaser }\end{array}$ & & & & & Costar \\
\hline \multicolumn{7}{|l|}{ Asset Attributes } \\
\hline SIZE & Floor area in square foot & $91.9 \mathrm{~K}$ & $142.7 \mathrm{~K}$ & 988 & $\begin{array}{r}3,706 \\
\mathrm{~K}\end{array}$ & STR \\
\hline ACRE & Land area in acres & 5.3 & 38.8 & 0.0 & 2200.0 & STR \\
\hline AGE & Age at the time of sale & 28 & 24 & 0 & 268 & STR \\
\hline ROOMS & Number of rentable rooms & 137 & 153 & 7 & 2,955 & STR \\
\hline FLOORS & Number of floors & 4.689 & & 1 & 60 & STR \\
\hline RESTAURANT & Dummy for restaurant on premise & 0.345 & & 0 & 1 & STR \\
\hline CONVENTION & Dummy for convention amenities & 0.034 & & 0 & 1 & STR \\
\hline CONFERENCE & Dummy for conference amenities & 0.006 & & 0 & 1 & STR \\
\hline GOLF & Dummy for golf amenities & 0.011 & & 0 & 1 & STR \\
\hline BOUTIQUE & Dummy for "boutique" category & 0.035 & & 0 & 1 & STR \\
\hline ALLSUITES & Dummy for "all suites" category & 0.150 & & 0 & 1 & STR \\
\hline CASINO & Dummy for casino amenities & 0.003 & & 0 & 1 & STR \\
\hline LEED & Dummy for LEED-label & 0.001 & & 0 & 1 & CoStar \\
\hline ES & Dummy for Energy Star-label & 0.007 & & 0 & 1 & CoStar \\
\hline \multicolumn{7}{|l|}{ Location Attributes } \\
\hline CBD & Dummy for CBD locality & 0.081 & & 0 & 1 & STR \\
\hline TAP1 & Dummy for Tapestries $1 \mathrm{~A}$ to $1 \mathrm{E}$ & 0.074 & & 0 & 1 & ESRI \\
\hline POPGR & $\begin{array}{l}\text { Population CAGR between } 2007 \text { and } \\
2012 \text { in the city }\end{array}$ & $0.91 \%$ & $0.86 \%$ & $1.8 \%$ & $5.1 \%$ & ESRI \\
\hline CAPMSA & $\begin{array}{l}\text { Dummy for whether the asset's } \\
\text { Metro area includes the state capital }\end{array}$ & 0.31 & & 0 & 1 & $\begin{array}{r}\text { US } \\
\text { Census }\end{array}$ \\
\hline
\end{tabular}

Further, to measure buyer aggressiveness, we document NETBUYING as the difference between assets purchased and sold by the same buyer. We also measure the relative aggressiveness between buyer and seller (GROSSBUYSELL) by calculating the difference of transaction activities between the buyer and seller of each transaction in our sample. For this dataset which measures buyer aggressiveness, we exclude the transactions where the buyer or the seller are not specified, thus reducing this sub-sample to 3,782. We also examine portfolio or multi-property sales. In such sales, if the price of an individual asset is not clearly known, CoStar "allocates" a proportionate price estimated based on sales-comparison approach applied to each asset in a transaction?

Impact of News Coverage

\footnotetext{
${ }^{7}$ https://www.costar.com/about/support/costar-glossary\#go_m
} 
One way to measure media-coverage is to add up the number of news articles in which a hotel is mentioned. However, this approach may overstate the amount of attention an asset receives. For example, TV news coverage for a particular event may be coupled with an equal number of newspaper articles for one event, even if the repetitive coverage does not double the status the hotel enjoyed by hosting the event. Rather, we need to focus on the latent tendency of an asset to grab attention which eventually manifests in various news sources such as newspaper or TV. Therefore, we collapse the amount of news from various sources into one factor (NEWSF) using exploratory factor analysis. We use NEWSF as an additional determinant of asset pricing.

Being mentioned in the news may imply the status of the event a hotel hosts and, by inference, the status of the asset itself. Therefore, being mentioned in the media should mostly have a positive impact on a hotel's conspicuity. However, such events tend to be hosted only in top tier (luxury or upper-upscale) hotels. Besides, collecting news-coverage information is a daunting, manual process. Therefore, we focus on a sub-sample of 641 luxury or upper-scale assets for this set of analyses. News indexing databases such as NEXIS provide detailed information about the media coverage based on keywords. We focus on news coverage before the asset transaction date.

\section{GIS Enhancements}

Being extremely superlative at the national level (i.e. the $99^{\text {th }}$ percentile of age, size or height) may be considered as a conspicuous asset attribute. However, an asset could also have locally extreme attributes because commercial assets tend to compete locally within their trade-areas, not nationally (Kimes and Fitzsimmons 1990). The demand generator for hotels, in particular, lie within specific driving distances (Rushmore 2012; Thrall 2002). Based on Rushmore (2012), we apply a Geographic Information System (GIS) tool to collect information within, 20-minutes driving distance $^{8}$ trade-area boundaries of each subject (i.e. sold) asset ${ }^{9}$. However, driving speeds vary across the regions and may be particularly high on highways. Therefore, the trade areas tend to be irregularly-shaped polygons as illustrated in Fig 1. On an average, these trade areas have 100 assets (ranging between 1 and 459, with a standard deviation of 80).

Earlier studies (Heffetz 2011; Corneo and Jeanne 1997) suggest that extremity matters only if the signaling value is "large enough". If the investment in a premium asset is motivated by an intent of showing off to others, or signaling superiority, merely enjoying the extreme status in an attribute within its neighborhood is inadequate. Rather, the extreme attributes must be conspicuous. However, traditional "atypicality" studies measure the deviation of an individual's specific attribute from its average across the full sample. Such an approach is exposed to two limitations. First, it discounts the phenomenon of "local extremes" as the deviations are calculated on national averages. For example, an asset may be locally the tallest, despite not being so nationally. Similarly, in downtown New York, an asset may be among the nationally tallest percentile, despite not being the tallest in the neighborhood. Second, this overstates the effects of extremity in environments of high variance and understates the extremes in environments with low variance. For example, while three extra floors may make a building stand out in a suburban area where most other buildings are of, say, two or three floors; such a difference will make little conspicuous impact in downtown Chicago where most buildings are tall, and their heights exhibit substantial variance. Therefore, to

\footnotetext{
${ }^{8}$ Anecdotal evidence suggests an average 18mph driving speed in US urban areas. Thus, a 20-minutes driving distance would roughly imply a 6-mile radius, on average.

9 The neighboring hotels includes sold and non-sold hotels
} 
incorporate both the deviation and variance, we calculate the Z-statistics $\left(Z_{k}=\frac{k_{i}-\bar{k}}{\sigma_{k}}\right)$ of an asset's attributes ${ }^{10}$. To identify assets with such attributes, we focus on those with $Z_{k}$ values of 1,2 and 3 . Thus, the Z-values specify the conspicuity of extreme attributes incrementally. For most attributes, we were able to identify several sold assets with locally extreme and conspicuous ${ }^{11}$ (i.e. $Z_{k} \geq$ 1,2 , or 3 ) size and height. However, the transaction dataset does not include any hotels that we identified as locally the oldest.

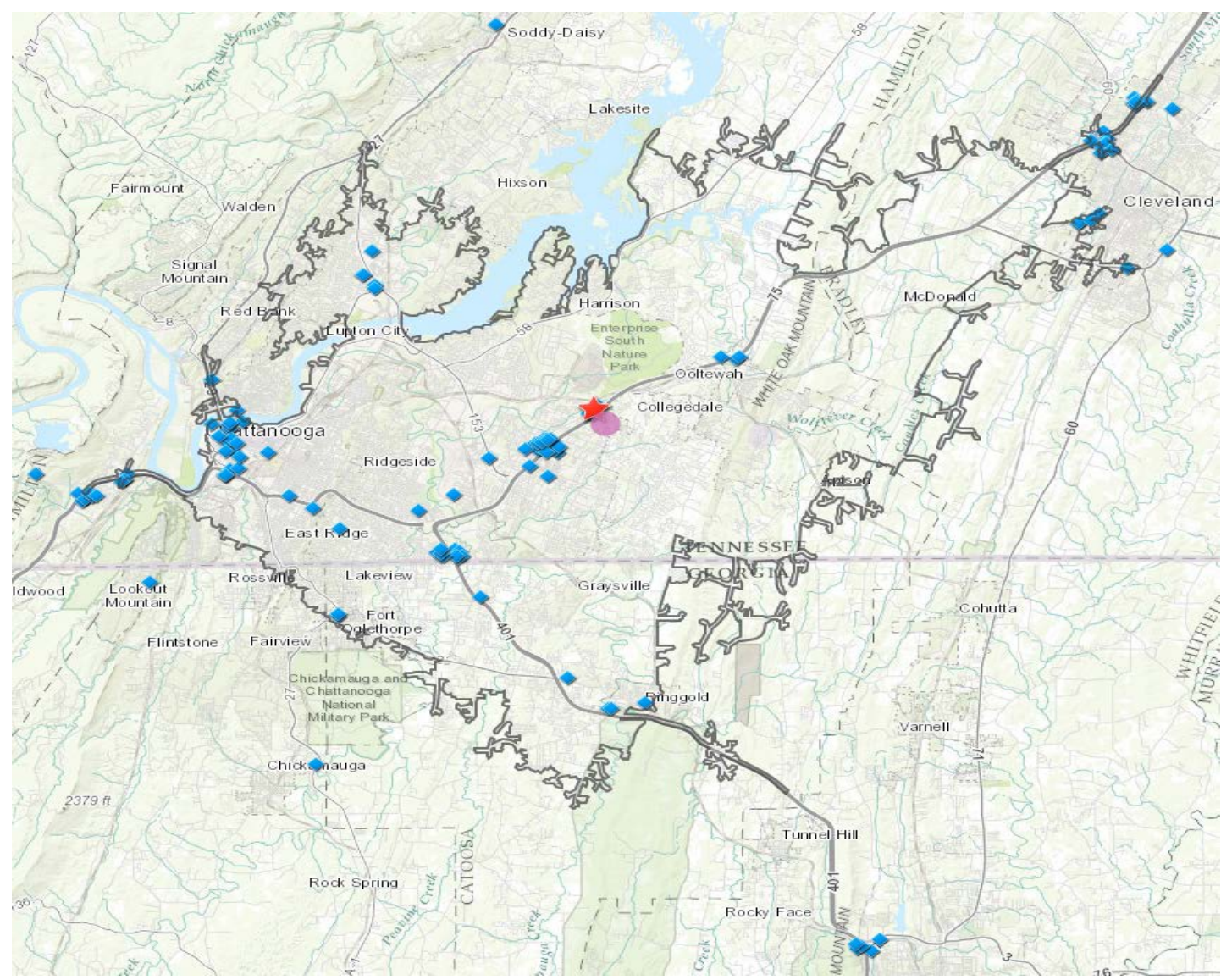

Fig. 1 Trade Area of a Hotel defined by 20-minutes Driving Distance.

Notes: This example shows the trade area of a subject hotel (marked as a star) defined by a polygon whose edges are at a 20-minutes driving distance from the hotel. The purple dot in the center of the map is the centroid of the polygon. Diamond shaped points identify hotels in the neighborhood within and beyond the subject hotel's trade area.

Further, the price of a sold asset (if itself not characterized by an extreme attribute) may be influenced by the externality generated from neighboring assets with extremely superlative attributes (Corneo and Jeanne 1997; Leguizamon 2010). Using the GIS technology we summarize such data. However, for each such asset without an extreme $\mathrm{k}$ there will be another in the trade area with the locally extreme attribute $k$. Therefore, against each such asset attribute, we focus on other

\footnotetext{
${ }^{10}$ Here, $i$ indexes a subject hotel; $\bar{k}$ and $\sigma_{k}$ denote mean and standard deviation of the attribute $\mathrm{k}$ among all hotels within the trade area of a subject hotel. In all Z-Statistic calculations, groups with zero standard deviation are assigned a Z-statistic of zero.

${ }^{11}$ such that $Z_{k=\text { Age }} \geq 2$
} 
assets which are conspicuously extreme (i.e. $Z_{k} \geq 1$, 2 or 3). The summary of trade-area extremities is presented in Table 2. Roughly, 1-3\% of the sold assets are among the nationally extreme (oldest, largest or tallest). Nearly 4-6\% are the locally largest or tallest. At higher degree of conspicuity (Zvalues), the representation of extreme attributes falls. Note that these percentages are based on the sample of sold assets. If the census of assets is included, these assets with extreme attribute represent a very small percentage ${ }^{12}$ (i.e. $0.1 \%$ to $0.6 \%$ ) of the hotel population.

\section{Empirical Methodology}

\section{Step-1: Baseline Hedonic Model}

Hedonic models, such as the ones applied in this study, can be construed as a sophisticated sales comparison method of valuation that prices individual asset attributes. The method is applicable to the determination of cash flows (Hung, Shang and Wang 2010; Lee and Jang 2012) as well as the price (Corgel, Liu and White, 2015) of an asset. Besides, cash flows and price are related to each other through capitalization rate which is a function of asset class, location and time. Most hedonic models already control for these factors. Therefore, exclusion of asset-specific cash flow data does not inhibit the efficacy of hedonic models, as shown in Corgel et al. (2015). The observed transaction price of an asset, in excess of its expected intrinsic value is indicative of its premium status. However, a naïve classification based on prices without controlling for the asset attributes may be misleading. We identify premium assets based on excess price they enjoy compared to their quality-controlled predicted price from the baseline hedonic model. In the first stage of our analysis, we run a traditional hedonic pricing model for transaction price (PRICE) as shown below:

$$
\begin{aligned}
& \operatorname{Ln}\left(P R I C E_{i}\right)=w(P, H, M, Q)_{i}+\epsilon_{i} \\
& \text { And } \epsilon_{i}=v_{i}+\varepsilon_{i}
\end{aligned}
$$

Here $P R I C E_{i}$ denotes the observed transaction price, and $w(.)_{i}$ denotes the (intrinsic) value predicted by a conventional (baseline) hedonic model with $\epsilon_{i}$ as the unexplained portion of PRICE. Subscript $i$ indexes individual asset transactions. $v$ is the portion of $\epsilon$ which is explained by extremity in asset attributes and $\varepsilon$ is the residual price variation. Since the above model uses logarithmic transformation of the dependent variable (i.e. sale price), the exponent of its residuals implies the multiplicative premiums (or discounts) implied in the observed transaction price.

$\mathrm{P}$ represents physical attributes of the asset (such as number of rooms, land area, number of floors, amenities, etc.). $\mathrm{H}$ is a set of variables specific to the hospitality industry and includes information related to operations such as location-classification (e.g. airport versus resort), class (e.g. luxury versus economy) and asset brand at the time of sale. The STR classification of asset classes is based on their room-price ranges and are broadly reflective of the "present value" variables as examined in Corgel et al. (2015). Floor area, and number of rooms are introduced as their natural logarithms. M and Q control for asset location and time of sale respectively.

We also include quadratic transformations of age and number of floors. We hypothesize nonmonotonic association of real estate prices with property age and number of floors. The vintage

\footnotetext{
${ }^{12}$ Of the 55,000 hotels in the STR's census, we have transaction details on approximately 4,800 hotels. 5\% of these sold hotels equal $0.45 \%=\frac{5 \% * 4,800}{55,000}$ of the population.
} 
effect in pricing due to age is well documented (Lin, Rosenblatt, and Yao 2009; Smith 2004) such that the prices first fall with age until they hit a critical age after which the association between price and age turns positive. The quadratic association of the price with number of floors is based on earlier studies (Brennan et al. 1984; Slade 2000).

Table 2 Extreme Attributes Within the Sample of Sold Hotels

\section{Panel 1. Nationally Extreme Attributes}

\begin{tabular}{lc}
\hline Nationally.Oldest & $1.1 \%$ \\
Nationally.Largest & $2.1 \%$ \\
Nationally.Tallest & Panel 2. Extreme Attributes of Subject Assets \\
\hline & $2.5 \%$ \\
\hline Trade_Area.Largest & $4.1 \%$ \\
Trade_Area.Tallest & $5.5 \%$ \\
Z1.Trade_Area.Largest & $3.8 \%$ \\
Z1.Trade_Area.Tallest & $4.5 \%$ \\
Z2.Trade_Area.Largest & $2.6 \%$ \\
Z2.Trade_Area.Tallest & $2.6 \%$ \\
Z3.Trade_Area.Largest & $1.2 \%$ \\
Z3.Trade_Area.Tallest & $1.8 \%$ \\
\hline & \\
\hline XZ1.Trade_Area.Oldest & Panel 3. Extreme Attributes of Neighboring Assets \\
XZ1.Trade_Area.Largest & $99.3 \%$ \\
XZ1.Trade_Area.Tallest & $95.7 \%$ \\
XZ2.Trade_Area.Oldest & $94.0 \%$ \\
XZ2.Trade_Area.Largest & $88.6 \%$ \\
XZ2.Trade_Area.Tallest & $89.8 \%$ \\
XZ3.Trade_Area.Oldest & $89.5 \%$ \\
XZ3.Trade_Area.Largest & $53.9 \%$ \\
XZ3.Trade_Area.Tallest & $76.9 \%$ \\
\hline Nor:Thisterepors & $78.8 \%$ \\
\hline
\end{tabular}

Notes: This table reports summary of the extreme asset attributes within the trade areas of subject (sold) hotels. The trade-area of a hotel is defined as a polygon encompassing a 20 minute driving distance. The analysis is applied to hotel sales in the US during 1991 to 2013. "Oldest" is based on the age of hotels within the trade area at the time of sale. Similarly, "Largest" and "Tallest" are based on the number of rooms and number of floors respectively. Panel 1 provides the percent of hotels in the sold sample recognized among the top $1 \%$ nationally based on the specified attributes. Panel 2 provides the extreme attributes of the subject (sold) hotels. Z1, Z2 and Z3 prefixes signify that the extreme attributes exceeded one, two or three (respectively) standard-deviations from the mean of the trade-area hotels. Panel 3 provides the extreme attributes of a neighboring hotel (relative to the sold hotels), if the subject hotel itself does not assume the extreme attribute. Thus, " $X$ " in the prefix signifies an external asset with extreme attributes. XZ1, XZ2 and XZ3 prefixes signify that the extreme attributes exceeded one, two or three (respectively) standard-deviations from the mean of the trade-area hotels.

However, these studies focus on the changing slope (coefficient) with the determinant rather than the non-monotonic association. A polynomial transformation (such as $F L O O R S^{2}$ ) implies that in different ranges of the FLOORS, the association shows different signs with the dependent variable (PRICE). While the positive association would affirm the above mentioned studies, the negative association is hypothesized in buildings considered as "too tall”. Studies have also shown 
significant association between eco-labels (LEED, ES) and commercial real estate prices in general (Eichholtz, Kok and Quigley 2010; Das and Wiley 2014) and hotel prices in particular (Robinson, Singh and Das, 2016).

Issues with Model Misspecification

We hypothesize that the baseline model in (5) can be enhanced by including the extreme positioning of an asset's physical attributes $\mathrm{P}=\left\{k_{1}=\mathrm{AGE}, k_{2}=\mathrm{ROOMS}, k_{3}=\mathrm{FLOORS}\right\}$ as follows:

$$
\operatorname{Ln}\left(P R I C E_{i}\right)=w(P, H, M, Q)_{i}+\gamma V_{i}+\varepsilon_{i}
$$

Where $\gamma V=v$ and $\gamma$ is a 3x1 matrix of coefficients and $\mathrm{V}$ is a 3x1 matrix of dummy variables $\left(v_{k_{i}}{ }^{\prime} s\right)$ specifying extreme physical attributes (oldest, largest, tallest). In this specification, the $v_{k_{i}}$ will be collinear with attribute $k$. Thus, $v_{k}$ is a function of $\mathrm{P}$ :

$$
v_{k}=\mathrm{g}(\mathrm{P})
$$

However, according to our hypothesis, $v_{k}$ is also a potential determinant of Ln(PRICE). Thus, the error term $\in$ in (5) is correlated with $\mathrm{P}$, an explanatory variable as well as with the dependent variable. This may potentially lead to omitted variable bias which we test for empirically.

\section{Step-2: Quantile Regression Models}

In the next step, we regress the $\epsilon$ extracted from the baseline hedonic model using extreme asset attributes as explanatory variable. Based on the quantiles of $\epsilon$, we categorize the assets into premium $(\epsilon>0)$ and discount $(\epsilon<0)$ segments $\forall i$. While an OLS-based hedonic model identifies the determinants of $v$, it cannot answer the following question: do these determinants influence asset prices differently across different quality-controlled premium ranges? This question is particularly important in this study as we are interested in the phenomenon of separating equilibrium across premium and discount segments. To address this issue, we employ quantile regression model based on earlier real estate studies (McMillen 2008; Zietz, Zietz and Sirmans 2008). A quantile regression of the qth quantile of the dependent variable $\left(v_{i}\right)$ minimizes the weighted sum of absolute deviations (Zietz et al. 2008):

$$
\min _{b_{j}^{m}} \sum_{j=0}\left|v_{i}-\sum_{j=0}^{m} b_{j} k_{j, i}\right| h_{i}
$$

where $i$ indexes an asset, $j$ indexes extreme attributes ( $k$ 's), $b$ 's are the regression coefficients and $h$ is the weight. For positive errors in (9), $h=2 q$ and $h=2-2 q$ for negative errors. Separating equilibrium with respect to an attribute $k_{j}$ implies that its coefficient $b_{j}$ is different across the premium and discount quantiles. We employ ANOVA to test for difference in coefficients across the quantiles. Separating equilibrium is confirmed if $\left.b_{j}\right|_{\text {premium }} \neq\left. b_{j}\right|_{\text {discount }}$. This can be confirmed if $\left.A N O V A_{N U L L:} b_{j}\right|_{\text {premium }}=\left.b_{j}\right|_{\text {Discount }}$ is rejected (i.e. F-stat leads to a p-value $\leq 5 \%$ ). Although rejecting the $A N O V A_{N U L L}$ is an evidence that $e_{V K} \neq 1$ (i.e. $e_{V K}>1$ or $e_{V K}<1$ ), quantile plots offer a more comprehensive method of detecting the separating equilibrium. Quantile plots provide a lucid summary of how various coefficients of the same variable compare to each other across different quantiles of the dependent variable. 


\section{Results and Discussion}

\section{Baseline Models}

The first model in Table 3 provides the results of (5). This "baseline" hedonic model has an adjusted $R^{2}$ of $83 \%$. Each percent increase in the floor area and number of rooms are independently associated with 0.2 and 0.4 percent increase in the asset price. Consider an asset with 100 rooms and 100,000 SF floor area worth $\$ 15 \mathrm{mi}$. 10 percent increase in size (i.e. 10 rooms $=10,000 \mathrm{SF}$ ) will lead to a price increase of $(0.2+0.4) * 10 \%=6 \%$ or approximately $\$ 900,000$ after controlling for other factors. Land owned by a hotel impacts the price positively, although the impact is minimal. In particular, an extra acre of land only improves the price by $0.004 \%$.

We find a non-monotonic association between the asset price and building height (FLOORS). Up to roughly 18 floors, each extra floor adds nearly $2 \%$ to the price. However, the price starts to fall by the same extent with each additional floor ${ }^{13}$. Upper floors in buildings considered too tall provide inferior visual amenity and complicated vertical transportation compared to moderately tall buildings. Besides, upper floors in such buildings may sway several inches (Jeary, Morris and Tomlinson 1988) due to wind ${ }^{14}$ raising the psychological issues of security (Gifford, 2007). The issues of fire safety (Pauls, 1987) also aggravates the safety concerns.

We detect a strong vintage effect in pricing. Prices decrease as age increases (roughly $0.4 \%$ per year) until the hotel's age reaches approximately 100 years - after which, prices start to increase with age at the same rate ${ }^{15}$. These findings are consistent with the expectations we present in the methodology section. In this model, we did not find any significant impact of eco-labels. A large number of dummy variables (asset brands, submarkets and the quarter of sale) are not reported in the table for brevity. However, a brief synopsis of these findings is reported below.

Only a few asset brands show price premiums (discounts) that are statistically significant. Lack of statistical significance in brands may be explained by the fact that brands are closely related with several other variables (such as asset type, location, amenities, etc.) which we are separately controlling for in the model. Nevertheless, our finding implies that brand name is priced in some cases even after controlling for measurable attributes typically associated with the brand. However, some brands may have had the tendency to systematically sell over-performing or underperforming assets during our period of analysis. The asset brand, however, does not imply a specific operational model. For example, a Hilton-branded asset may be managed by a separate entity (as in a "franchise contract" with Hilton), or by Hilton itself (typically as a "management contract" with Hilton). Yet, we find that the operational model of the hotel at the time of sale has no significant impact on pricing.

\footnotetext{
${ }^{13} 0.035 *$ FLOORS -0.001 FLOORS $^{2}=0.306-0.001 *(\text { FLOORS }-17.5)^{2} ;$ Also, $\frac{0.306}{17.5} \approx 2 \%$

${ }^{14}$ http://www.npr.org/2011/11/07/141858484/how-the-worlds-tallest-skyscrapers-work

$15-0.008 * \mathrm{AGE}+0.00004 * \mathrm{AGE}^{2}=-0.4+0.00004 *(\mathrm{AGE}-100)^{; 2}$ Also, $\frac{0.4}{100} \approx 0.4 \%$
} 
Table 3 Baseline Models of Hotel Transaction Prices

\begin{tabular}{|c|c|c|c|c|}
\hline & Baseline & Location Attributes & News Coverage & Transaction Attributes \\
\hline Constant & $10.858 * * *(0.765)$ & $10.660 * * *(0.768)$ & $8.487 * * *(1.236)$ & $10.074 * * *(0.832)$ \\
\hline $\ln (\mathrm{SIZE})$ & $0.188 * * *(0.019)$ & $0.188 * * *(0.019)$ & $0.364 * * *(0.064)$ & $0.219 * * *(0.021)$ \\
\hline ACRE & $0.001 * *(0.0003)$ & $0.001 * *(0.0003)$ & $-0.00003(0.001)$ & $0.0004(0.0005)$ \\
\hline AGE & $-0.008 * * *(0.001)$ & $-0.008 * * *(0.001)$ & $-0.003(0.003)$ & $-0.007 * * *(0.001)$ \\
\hline $\mathrm{AGE}^{2}$ & $4 \mathrm{E}-5 * * *(0.00001)$ & $0.00004^{* * *}(0.00001)$ & $0.00003(0.00002)$ & $4 \mathrm{E}-5 * * *(0.00001)$ \\
\hline $\log (\mathrm{ROOMS})$ & $0.427 * * *(0.026)$ & $0.429 * * *(0.026)$ & $0.382 * * *(0.096)$ & $0.416^{* * *}(0.029)$ \\
\hline FLOORS & $0.035 * * *(0.006)$ & $0.036 * * *(0.006)$ & $0.038 * * *(0.014)$ & $0.031 * * *(0.006)$ \\
\hline FLOORS $^{2}$ & $-0.001 * * *(0.0001)$ & $-0.001 * * *(0.0001)$ & $-0.0005 *(0.0003)$ & $-0.001 * * *(0.0001)$ \\
\hline LEED & $-0.168(0.218)$ & $-0.164(0.218)$ & $0.359(0.380)$ & $0.247(0.234)$ \\
\hline ES & $0.121(0.103)$ & $0.129(0.103)$ & $0.168(0.235)$ & $0.191 *(0.107)$ \\
\hline CBD & $1.409 * * *(0.234)$ & $1.320 * * *(0.248)$ & $1.066(0.699)$ & $1.848 *(1.045)$ \\
\hline TAP1 & & $0.111^{* * *}(0.036)$ & $0.154(0.198)$ & $0.136 * * *(0.040)$ \\
\hline POPGR & & $0.0005(0.016)$ & $-0.197 *(0.102)$ & $-0.008(0.019)$ \\
\hline CAPMSA & & $0.085(0.080)$ & $-0.582(0.725)$ & $0.081(0.095)$ \\
\hline NEWSF & & & $0.005 * * *(0.002)$ & \\
\hline INVESTMENT & & & & $0.137 * * *(0.052)$ \\
\hline SELFRUN & & & & $0.092(0.068)$ \\
\hline PORTFOLIO & & & & $0.176^{* * *}(0.035)$ \\
\hline MULTIPROPERTY & & & & $-0.126 * * *(0.048)$ \\
\hline NETBUYING & & & & $0.002 * *(0.001)$ \\
\hline GROSSBUYSELL & & & & $0.003^{* * *}(0.001)$ \\
\hline Operational model & Yes & Yes & Yes & Yes \\
\hline Class & Yes & Yes & Yes & Yes \\
\hline Amenities & Yes & Yes & Yes & Yes \\
\hline Location type & Yes & Yes & Yes & Yes \\
\hline Brand & Yes & Yes & Yes & Yes \\
\hline
\end{tabular}




\begin{tabular}{lcccc} 
Submarket & Yes & Yes & Yes & Yes \\
Quarter dummies & Yes & Yes & Yes & 5,778 \\
\hline$N$ & 4,784 & 4,784 & 0.921 & 0.878 \\
$\mathrm{R}^{2}$ & 0.859 & 0.859 & 0.807 & 0.845 \\
Adjusted R & 0.829 & 0.829 & $8.081^{* * *}$ & $26.630^{* * *}$ \\
F Statistic & $28.659^{* * *}$ & $28.625^{* * *}$ & \\
\hline
\end{tabular}

Notes: This table shows OLS regression coefficient estimates for hedonic models where $\ln ($ SALEPRICE) is the dependent variable. The analysis is applied to hotel sales in the U.S. from 1991 to 2013. Quantities in parentheses denote standard errors. ***, ** and * denote statistical significance at $1 \%, 5 \%$ and $10 \%$ levels, respectively. SALEPRICE $=$ transaction price. SIZE $=$ floor area in square foot. ACRE = land area in acres. AGE = age at the time of sale. ROOMS = number of rentable hotel rooms. FLOORS $=$ number of floors. LEED = dummy for LEED label. ES = dummy for Energy Star label. CBD = dummy for CBD locality. TAP1 indicates whether the asset is located in "affluent" tapestry segments as categorized by ESRI. POPGR = CAGR of population in the city between 2007 and 2012. CAPMSA = Dummy for whether the asset's Metro area includes the state capital. NEWSF measures media coverage of a hotel based on a unidimensional factor developed from data across several media outlets (only applicable to a limited sample of Luxury and Upper-upscale hotels. INVESTMENT = dummy specifying third-party tenant at the time of sale. SELFRUN = dummy specifying self-operated hotel by the owner. PORTFOLIO = dummy for a portfolio sale. MULTIPROPERTY = dummy for a multi-property sale. NETBUYING measures the net buying (buying minus selling) activity of the buyer from all hotel transactions in the sample. GROSSBUYSELL measure the difference of transaction activities (buying of selling) across the buyer and the seller of a given transaction across all transactions in the sample. Operational models include dummy variables for various hotel operation models, namely: Independent, Franchise or Chain Management. Hotel Classes includes dummy variables for various hotel classes, namely: Economy, Luxury, Midscale, Upper Midscale, Upper Upscale, and Upscale. Amenities refer to dummy variables for: restaurant, golf, casino, convention, conference, boutique, all-suites, casino and golf. Location type includes dummy variables for various hotel location-types, namely: Airport, Interstate, Resort, Small Metro, Suburban, and Urban. Brand is the Brand at the time of sale. Quarter denotes dummy variable for the time of sale in terms of year-quarter. Submarket denotes dummy variables for market tracts. 
As expected, we find that submarkets show statistically different price premiums (discounts) ${ }^{16}$. We also find that various asset classifications are relevant. For example, compared to the "economy class" segment, prices increase as the segment classification improves. Midscale, upper midscale and upscale segments enjoy price premiums of $14 \%, 30 \%$ and $65 \%$ respectively compared to economy class. Upper-upscale and luxury class assets are priced nearly double or triple the price of an otherwise fairly similar economy asset. Asset typology based on the location is broadly insignificant. However, compared to airport assets, resorts enjoy a 35.7\% premium while other assets do not show significant premiums or discounts.

The second specification in Table 3 tests if specific location characteristics have a marginal impact on asset pricing. We find that affluent locations (TAP1) are associated with a nearly $12 \%$ price premium ${ }^{17}$. However, we find that population growth in the city or the state-capital metro areas are not significantly associated with prices. The third specification in Table 3 includes the news coverage variable. The results suggest that news coverage has significant, positive impact on asset pricing - although as discussed earlier the variable is highly correlated with specific hotel segments (luxury and up-scale), so this finding is not surprising.

Table 4 Summary of Extreme Asset Attributes Across the Range of Baseline Residuals

\begin{tabular}{lcccccc}
\hline & \multicolumn{3}{c}{ Top (Premium) Quantiles } & \multicolumn{3}{c}{ Bottom (Discount) Quantiles } \\
\hline Quantiles & $\begin{array}{c}95^{\text {th }} \text { and } \\
\text { Above }\end{array}$ & $\begin{array}{c}90^{\text {th }} \text { and } \\
\text { Above }\end{array}$ & $\begin{array}{c}75^{\text {th }} \text { and } \\
\text { Above }\end{array}$ & $\begin{array}{c}25^{\text {th }} \text { and } \\
\text { Below }\end{array}$ & $\begin{array}{c}10^{\text {th }} \text { and } \\
\text { Below }\end{array}$ & $\begin{array}{c}5^{\text {th }} \text { and } \\
\text { Below }\end{array}$ \\
\hline Observations & 240 & 479 & 1,196 & 1,196 & 479 & 240 \\
\hline Residuals & 0.6935 & 0.5263 & 0.2617 & -0.2421 & -0.5143 & -0.7196 \\
\hline Multiplicative Premia or & $2 \mathrm{X}$ & $1.69 \mathrm{X}$ & $1.3 \mathrm{X}$ & $0.79 \mathrm{X}$ & $0.6 \mathrm{X}$ & $0.49 \mathrm{X}$ \\
Discounts = EXP(Residuals) & $100 \%$ & $69 \%$ & $30 \%$ & $-21 \%$ & $-40 \%$ & $-51 \%$ \\
\hline Linear Premia or Discounts & & & & &
\end{tabular}

This table compares the residuals of baseline hedonic model for across its own quantile intervals. The baseline hedonic model includes the natural log of hotel sale price as the dependent variable which has a high explanatory power. The independent variables includes an exhaustive set of hotel, location and time attributes.

In the fourth specification, characteristics of the asset transaction and buyers are introduced. Corgel et al. (2015) suggest that it is difficult to hypothesize the price impact of an asset when it is sold as a part of a portfolio or multi-property sale transaction. This model suggests that assets tended to assume $18 \%$ higher (12\% lower) values compared to their intrinsic value if they were part of a portfolio (multi-property) sale. Some buyers may operate the acquired asset themselves (SELFRUN) while other will treat it as an investment (INVESTMENT) targeted at third-party asset operators. In line with Corgel and deRoos (1994) and Nesbitt and Phen (1995) we find that buyers pay up to $14 \%$ higher price if they are expressly acquiring a hotel for investment purposes compared to ones where the buyer intention is not specified. Buyer aggressiveness (NETBUYING, GROSSBUYSELL) in the asset-transactions market has a marginal (0.2\%-0.3\%), yet significant positive association with the price. Inclusion of these variables improves the predictive ability

\footnotetext{
${ }^{16}$ Based on their coefficients, top-10 and bottom-10 markets are listed in Appendix Table1.

${ }^{17} e^{0.111}-1=11.7 \%$
} 
(Adjusted $R^{2}=85 \%$ ) of the model. As expected, we find that strong investment demand and buyer aggressiveness are associated with higher prices. Yet, based on earlier studies, we use the first specification as the baseline model going forward.

\section{Price Variations Unexplained by the Baseline Model}

The unexplained price component from the baseline model $(\epsilon)$ becomes the dependent variable in the next stage. Fig 2 plots the residuals from the baseline model. The probability distribution suggests an approximately normal QQ plot and slightly leptokurtic residuals with nearly zero skewness ${ }^{18}$. The tails are slightly fatter compared to the normal distribution implying that there are several assets in the extreme premium and discount segments. The negative and positive $\in$ ' $s$ are symmetrically distributed around the median (where $\in=0.005$ ). Table 4 describes the residuals at some discrete quantiles. From Table 4, assets in the premium (discount) quantiles are priced $100 \%$ higher (50\% lower) compared to the baseline predictions. Thus, there is a four-fold variation in pricing across the segments that the baseline hedonic model fails to explain.

QQ Plot of Studentized Baseline Residuals

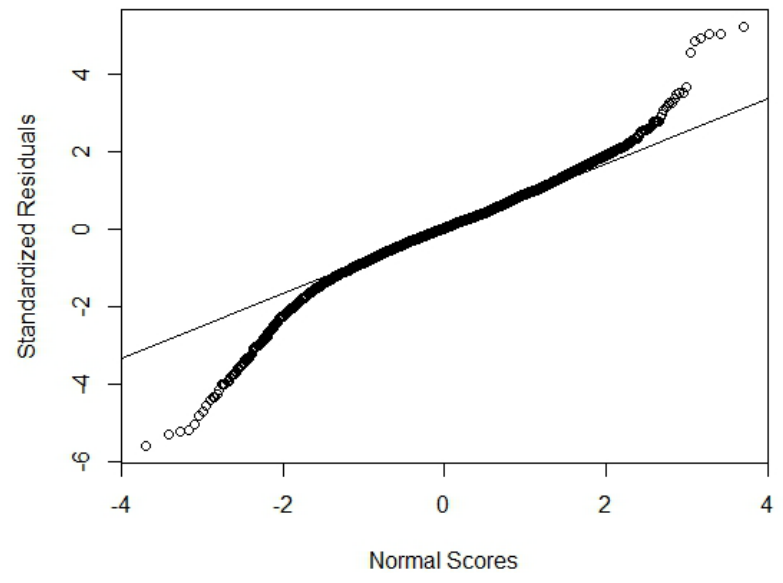

Distribution of Studentized Baseline Residuals

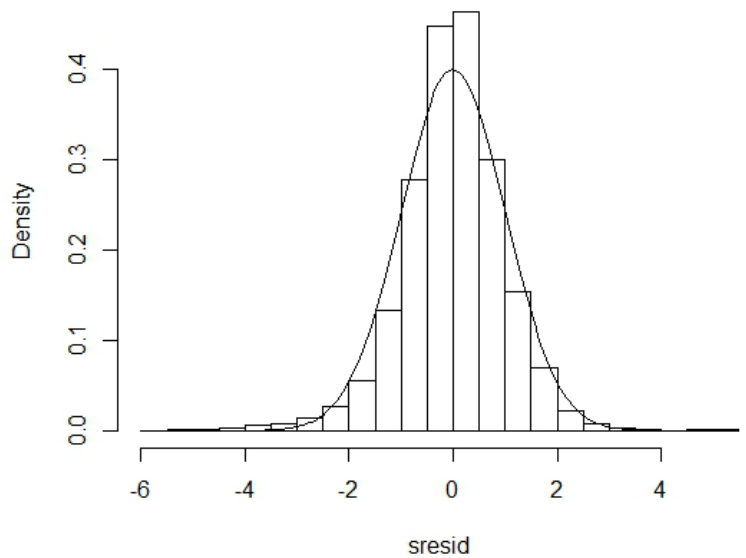

Fig 2 Residuals from the Baseline Hedonic Model

Fig 3 suggests that the premium and discount segments are equally distributed across the United States, implying the limited role of geographic boundaries in explaining $\in$. Some other candidates for explaining the $\in$ are (a) asset class and (b) location status and (c) extreme asset attribute status.

For illustrative purposes, Table 5 describes how these three sets of attribute (a, b and c) are distributed across the $95^{\text {th }}$ (premium) and $5^{\text {th }}$ (discount) quantiles ${ }^{19}$. We see that the distribution of asset classes and location characteristics do not vary substantially across the premium and discount segments. However, there is drastic variation across the two segments with respect to an asset's extreme attributes. Further, Utts (1982) proposed the Rainbow test of linearity based on the null hypothesis that the regression coefficients in the baseline hedonic model is the same across the middle and extreme values of the regressors. We conduct this analysis for three variables of our interest: AGE, ROOMS and FLOORS. Table 6 suggests that extreme value of these variables are

\footnotetext{
${ }^{18}$ Skewness $=-0.44$, kurtosis $=5.6$

${ }^{19}$ For further details, see Appendix Table 2
} 
associated differently with the price. This supports our hypothesis that extreme asset attributes (i.e. set c) may be significant in explaining some variation in $\in$. Therefore, we enhance our baseline hedonic models by introducing these attributes.

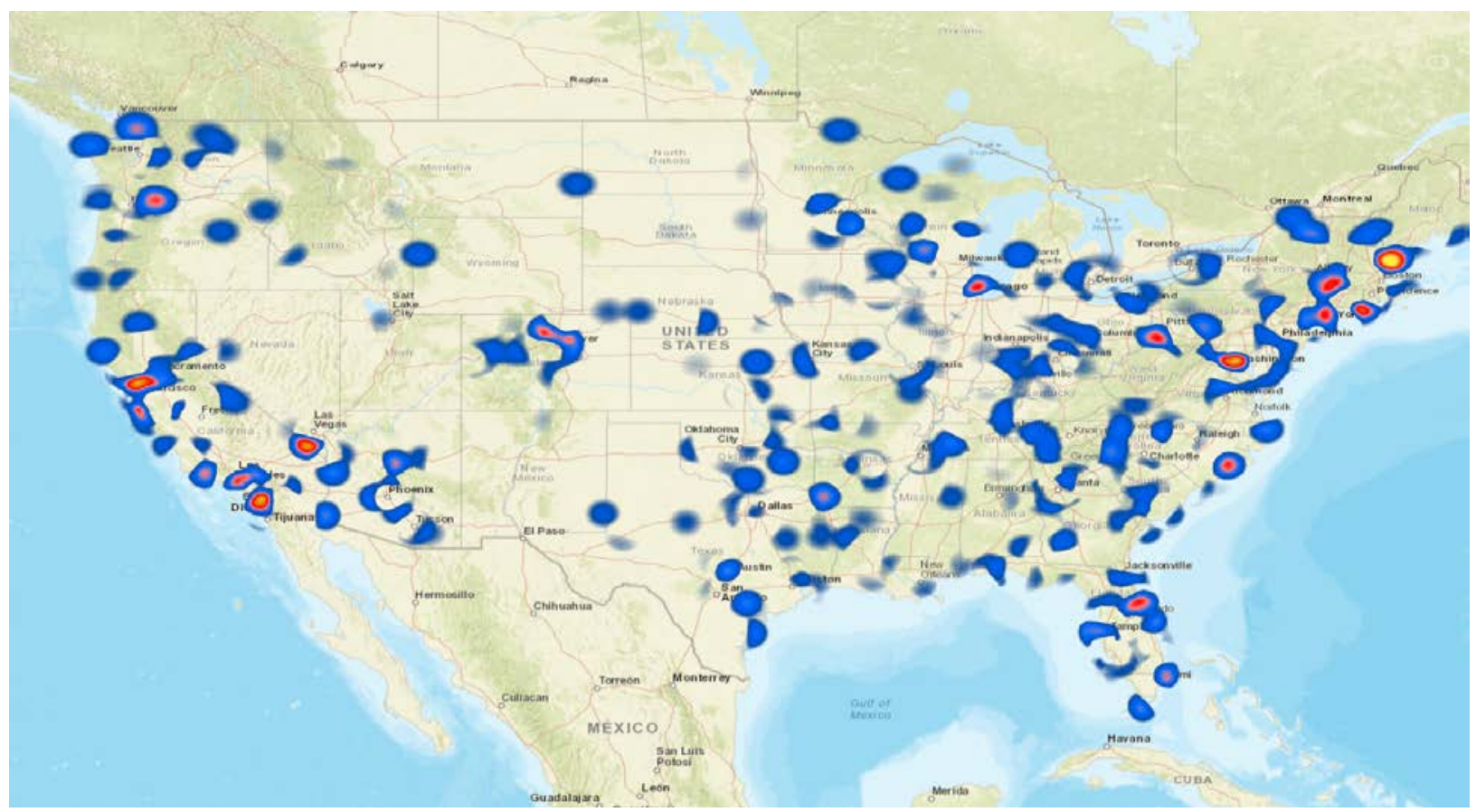

Fig 3 Heat Map of Premium and Discount Hotel Prices

Notes: This image depicts the geographic distribution of hotel prices unexplained by a baseline hedonic model (i.e. the model residuals). Warm colors (usually in the center of clusters) such as yellow, orange and red suggest premium prices whereas the shades of blue (dark to light) suggest discounts.

Table 7 describes the results of the enhanced analysis. The first specification includes an asset's own extreme characteristics. We find that being nationally the largest leads to a price premium of nearly $36 \%$ whereas the locally largest status is considered "atypical" and leads to nearly $13 \%$ discount. No other extreme attributes are statistically significant at this stage. In the second specification we include the externalities created by neighboring assets with extreme attributes. The externality variables also are statistically insignificant at this stage.

The evidence presented in Table 7 motivates additional analyses to examine (1) if the baseline model could be prone to omitted variable bias (OVB) and (2) if the baseline model is inadequately specified. We run three inadequacy tests and present the results in Table 8. To examine the OVB, we conduct Ramsey's Specification error test (RESET) wherein the square of the fitted value from the baseline model are included as additional regressors. We reject the null hypothesis of no OVB. This implies that the traditional baseline models are subject to omitted variable bias. Further, we conduct likelihood ratio (LR) tests based on the null hypothesis that the baseline model is adequately specified in absence of our proposed variables (as two different sets as in Table 7). The null is rejected for both the sets of additional regressors (extreme attributes) implying that the baseline models are inadequately specified. 
Table 5 Distribution of Attributes across Top 5\% (Premium) and Bottom 5\% (Discount) Assets

\begin{tabular}{lccc}
\hline Attributes & Premium Quantile & Discount Quantile & Premium/Discount \\
\hline Class & & & \\
Economy Class & $19.0 \%$ & $15.6 \%$ & $1.2 \mathrm{X}$ \\
Luxury Class & $7.4 \%$ & $7.1 \%$ & $1.1 \mathrm{X}$ \\
Midscale Class & $13.2 \%$ & $11.3 \%$ & $1.2 \mathrm{X}$ \\
Upper Midscale Class & $19.4 \%$ & $20.4 \%$ & $1.0 \mathrm{X}$ \\
Upper Upscale Class & $19.8 \%$ & $18.8 \%$ & $1.1 \mathrm{X}$ \\
$\quad$ Upscale Class & $21.1 \%$ & $27.9 \%$ & $0.8 \mathrm{X}$ \\
Location & & & \\
CBD & $14.9 \%$ & $13.3 \%$ & $1.1 \mathrm{X}$ \\
CAPMSA & $28.5 \%$ & $32.1 \%$ & $0.9 \mathrm{X}$ \\
POPGR & $0.98 \%$ & $1.00 \%$ & $1.0 \mathrm{X}$ \\
Extreme Attributes & & & \\
Nationally Oldest & $2.5 \%$ & $2.5 \%$ & $1.0 \mathrm{X}$ \\
Nationally Largest & $8.7 \%$ & $2.9 \%$ & $3.0 \mathrm{X}$ \\
Nationally Tallest & $5.8 \%$ & $3.8 \%$ & $1.5 \mathrm{X}$ \\
Trade-Area Largest & $3.7 \%$ & $7.1 \%$ & $0.5 \mathrm{X}$ \\
Trade-Area Tallest & $5.8 \%$ & $8.3 \%$ & $0.7 \mathrm{X}$ \\
\hline
\end{tabular}

Notes. This table describes how the asset attributes are distributed across two extreme quantiles (top $5 \%$ and bottom $5 \%$ ) of unexplained price variations (i.e. premiums and discounts, respectively). The premiums and discounts are derived from the $95^{\text {th }}$ and $5^{\text {th }}$ quantile thresholds of the residuals of a baseline OLS hedonic model. Trade-area of a hotel is defined as a polygon within 20 minutes driving distance. Nationally oldest, largest and tallest categories are based on the top $1 \%$ hotels based on the hotel age, number of rooms and number of floors respectively. CBD = dummy for CBD locality. TAP1 indicates whether the asset is located in "affluent" tapestry segments as categorized by ESRI. POPGR = CAGR of population in the city between 2007 and 2012. CAPMSA = Dummy for whether the asset's Metro area includes the state capital.

Table 6 Rainbow Test for Changing Slopes Across the Range of Explanatory Variables

\begin{tabular}{|c|c|c|}
\hline $\begin{array}{l}\text { Explanatory } \\
\text { Variable }\end{array}$ & Statistic & $\begin{array}{l}\text { Notes: This table provides the results of the Rainbow test of Linearity (Utts 1982). } \\
\text { The Null hypothesis is that the regression coefficients in the baseline hedonic model }\end{array}$ \\
\hline AGE & $1.28 * * *$ & is the same across the midc \\
\hline ROOMS & $1.27 * * *$ & asset \\
\hline FLOORS & $1.28 * * *$ & $\begin{array}{l}\text { OLS estimator. AGE, ROOMS and FLOORS (included in the baseline model, among } \\
\text { other explanatory variables) refer to age at the time of sale, number of rooms and } \\
\text { number of floors for each hotel included in the sample. }\end{array}$ \\
\hline
\end{tabular}


Table 7 Enhanced Models with Extreme Attributes and Externalities

\begin{tabular}{lcc}
\hline & Trade Area Extremes & Externality of Conspicuous Extremes \\
\hline Nationally Oldest & $-0.178(0.116)$ & $-0.179(0.116)$ \\
Nationally Largest & $0.306^{* * *}(0.075)$ & $0.306^{* * *}(0.075)$ \\
Nationally Tallest & $-0.083(0.084)$ & $-0.083(0.084)$ \\
Trade Area Largest & $-0.138^{* * *}(0.047)$ & $-0.136^{* * *}(0.048)$ \\
Trade Area Tallest & $-0.035(0.041)$ & $-0.028(0.044)$ \\
XZ3 Trade Area Oldest & & $-0.004(0.026)$ \\
XZ3 Trade Area Largest & & $0.003(0.031)$ \\
XZ3 Trade Area Tallest & & $0.012(0.033)$ \\
$N$ & 4,784 & 4,784 \\
$\mathrm{R}^{2}$ & 0.860 & 0.860 \\
Adjusted R & & 0.830 \\
F Statistic & 0.830 & $28.669^{* * *}(\mathrm{df}=846 ; 3937)$ \\
\hline
\end{tabular}

This table shows OLS regression coefficient estimates for hedonic models where ln(SALEPRICE) is the dependent variable. SALEPRICE is the transaction price. Other independent variables from the baseline model are also controlled for, but not reported in this table for brevity. The analysis is applied to hotel sales in the U.S. from 1991 to 2013. Quantities in parentheses denote standard errors. ***, ** and * denote statistical significance at 1\%, 5\% and $10 \%$ levels, respectively.

Table 8 Tests for Inadequacy of the Baseline Model

\begin{tabular}{|c|c|c|c|}
\hline Additional Regressors & Test & Statistic & $\begin{array}{l}\text { Null hypothesis for } \\
\text { the baseline model }\end{array}$ \\
\hline A. Square of the baseline fitted values & RESET & $31.45 * * *$ & $\begin{array}{l}\text { No Omitted variable } \\
\text { bias }\end{array}$ \\
\hline $\begin{array}{l}\text { B. Extreme asset characteristics: based on } \\
\text { national and trade-area comparisons }\end{array}$ & $\begin{array}{l}\text { Likelihood } \\
\text { Ratio }\end{array}$ & $54.49 * * *$ & $\begin{array}{l}\text { Adequacy of the } \\
\text { model }\end{array}$ \\
\hline $\begin{array}{l}\text { C. All in B plus conspicuous extreme } \\
\text { characteristics of neighboring assets within } \\
\text { the trade area }\end{array}$ & $\begin{array}{l}\text { Likelihood } \\
\text { Ratio }\end{array}$ & $54.81 * * *$ & $\begin{array}{l}\text { Adequacy of the } \\
\text { model }\end{array}$ \\
\hline
\end{tabular}

Notes: Each row provides the results from various specification error tests conducted on the baseline hedonic model. In the baseline hedonic model, natural log of asset prices are regressed on a set of standard asset and transaction characteristics using the OLS estimator. The first column is the test statistics based on the comparison between the baseline (i.e. restricted, as hypothesized) hedonic model and an alternate specification with additional set of regressors. *** indicates statistical significance at $1 \%$ level. Rejection of the null hypothesis implies that the baseline model is under-specified and may be prone to omitted variable bias. RESET test refers to Ramsey Regression Equation Specification Error Test (RESET). The alternate models in the likelihood ratio tests apply additional set of binary regressors which specify whether an asset has an extreme (superlative) standing nationally or locally with respect to an asset's age, size or height (i.e. relative to some variables already included in the baseline model). The trade area is defined as 20-minutes driving distance from the subject asset. 
Separating Equilibrium: Quantile Regression | “One man's meat is another man's poison”

Given the stylized facts in Table 5 (and Appendix Table 2) that suggest a separating equilibrium across the quantiles of $\in$, we examine the attributes through quantile regression. We could apply the quantile regression models on the hedonic models themselves. However, a very large number of regressors renders this task computationally infeasible. Conducting this analysis on the unexplained price (i.e. $\in$ ) from the baseline model addresses the issue, and leads to a parsimonious model which allows us to maintain our focus on the extreme attributes. We run the quantile regression across the range of $\in$ incrementally. Due to a large number of regression models across the quantiles, we present the quantile regression plots in Fig 4. The Fig shows how the coefficient estimates being plotted vary across the quantiles. The $\mathrm{X}$-axis for each plot depicts the quantiles of $\in$ and the Y-axis reports the coefficient values. The dashed horizontal lines are the confidence interval for a regular OLS model. The dotted curved lines are the coefficient estimate for the quantile regression and the corresponding confidence intervals are depicted by the grey band. The plots suggest that the insignificance of some extreme attributes in Table 7 may be related to the separating equilibrium (i.e. changing coefficient signs) across the various quantiles of the dependent variable.

Fig 4 plots the coefficients for a model that only includes an asset's own extreme attributes (within trade area and nationally). Whereas Fig 5 plots the coefficients for a model that also includes the externalities created by the presence of another asset in the neighborhood that has conspicuously ${ }^{20}$ extreme characteristics (variables with prefix “XZ1.”), and given the subject asset itself does not have the specific extreme attribute locally. To account for the conspicuity of the extreme attributes, we also run separate regression models where the extremities are recognized only if they exceed the local mean by certain Z-scores (1, 2 and 3). The plots are presented in the Appendix Figs 1 and 2. Also, a consolidated summary of the plots is presented in Table 9. The following discussion is based on the consolidated summary.

\section{Largest}

Being the locally largest asset has a negative coefficient independent of the quantiles or the conspicuity status (i.e. $Z \geq 1,2$ or 3). The finding is consistent with Kallberg, Liu, and Greig (1996) and Ziering and McIntosh (1999) who argue from a portfolio standpoint: very large assets exhibit higher volatility and are more highly correlated with other asset classes, leading to value loss. Extremely large assets in the locality are too specific and thus prone to atypicality discount, as reported in Blal and Graf (2013). Being the locally largest does not offer a strong-enough statusenhancement unless also clubbed with the nationally largest status. On the other hand, being among nationally the largest assets offers a distinguishing attribute which is value enhancing. The positive effect of being the nationally largest (1.36X) substantially surpasses the negative effect ${ }^{21}$ of being atypically the largest locally $(0.88 \mathrm{X})$. The equilibrium broadly stays stable across the premium and discount segments with respect to holding the locally or nationally largest status.

\footnotetext{
${ }^{20}$ All assets which do not have an extreme attribute will have another asset with the locally extreme attribute. To avoid the issue of almost perfect multicollinearity, we specifically include the neighboring assets whose extreme attributes exceed at least one standard deviation from the local mean (i.e. $\mathrm{Z} \geq 1$ )

${ }^{21}$ The net effect is $1.36 \times 0.88=1.20$
} 
(Intercept)

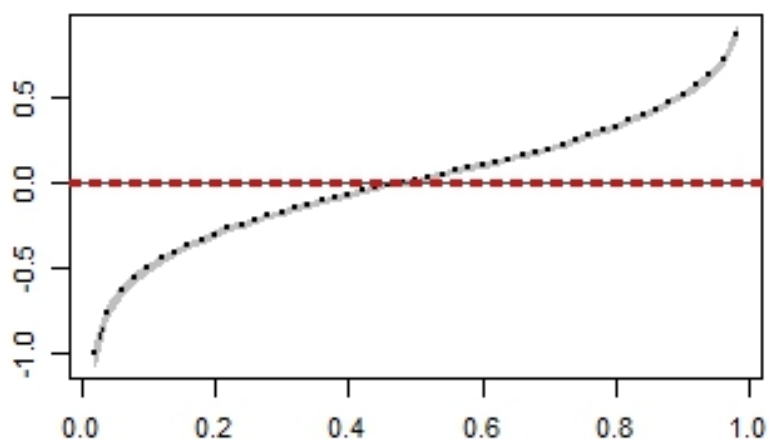

Trade_Area.Tallest

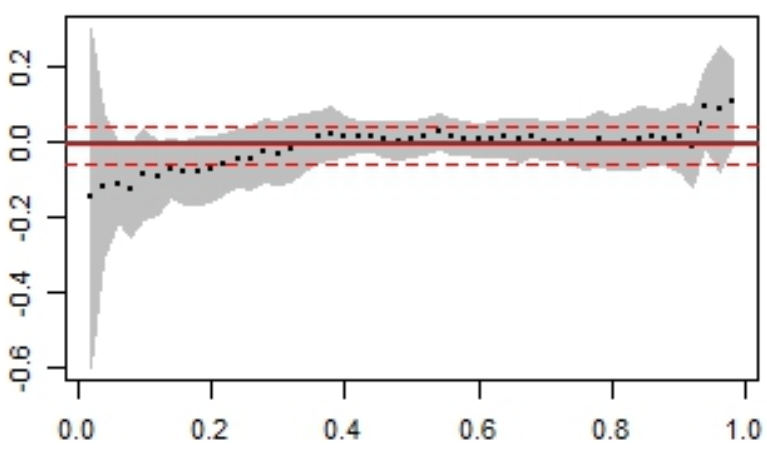

Nationally.Largest

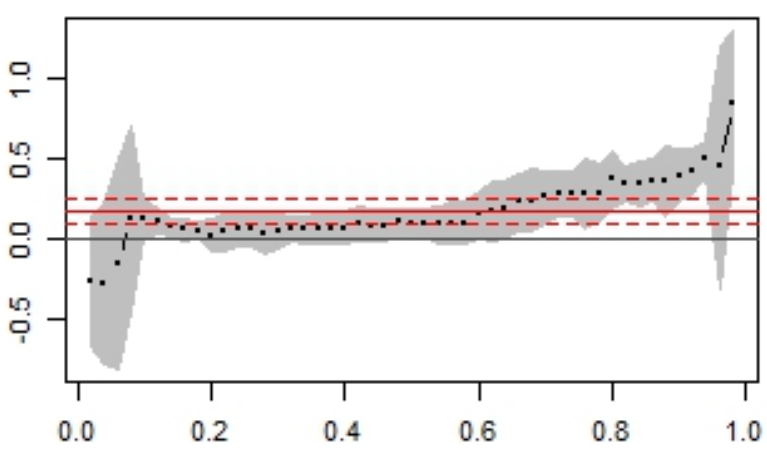

Trade_Area.Largest

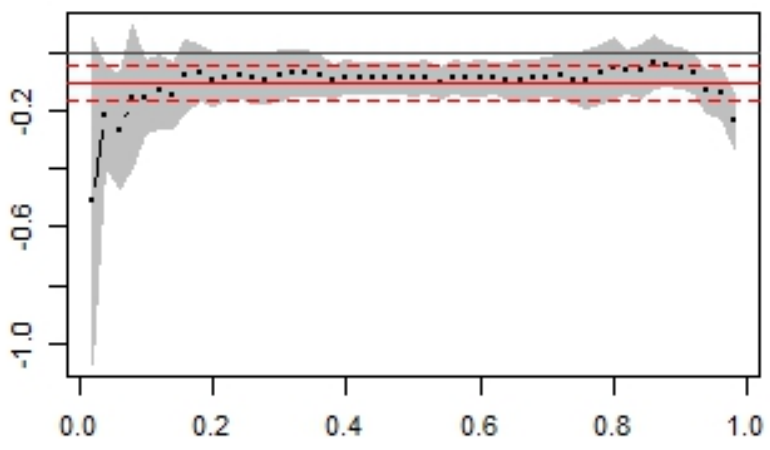

Nationally.Oldest

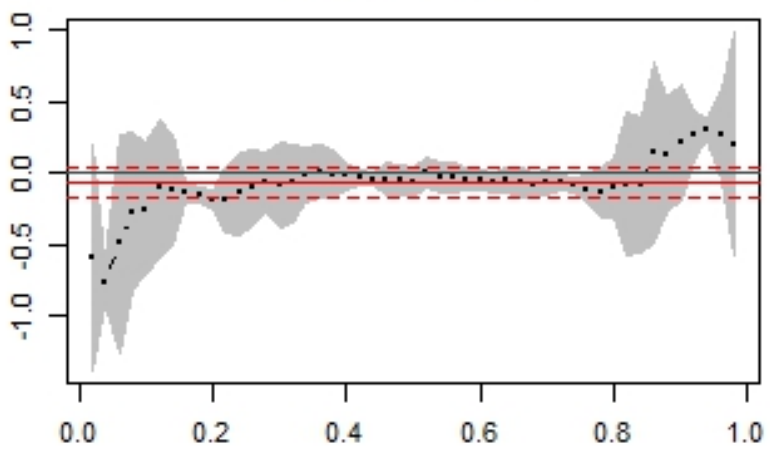

Nationally.Tallest

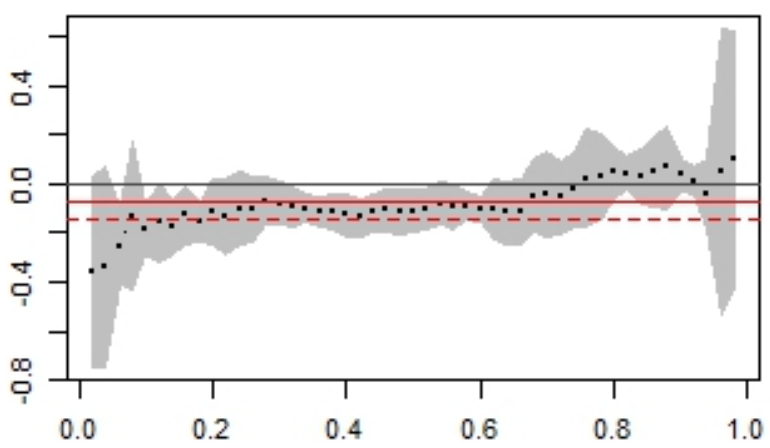

Fig 4 Baseline Quantile Regression Coefficient Estimates

Notes: This quantile regression plot depicts how the extreme attributes (specified plot titles) are differently associated with the dependent variable $(\epsilon)$ across its quantiles. $\in$ is the residual extracted from a baseline hedonic model of the natural log of sale price. The analysis is applied to hotel sales in the U.S. from 1991 to 2013 for a sample of nearly 4,800 hotel transactions. Dashed horizontal lines are the confidence interval for the baseline hedonic model applied to the same data. The dotted curve is the coefficient estimate from the quantile regression. Its confidence intervals are depicted by the grey band. Trade area refers to the 20-minutes driving distance radius surrounding a subject hotel. Nationally oldest, largest and tallest categories are based on the top $1 \%$ hotels based on the hotel age, number of rooms and number of floors respectively. 
(Intercept)

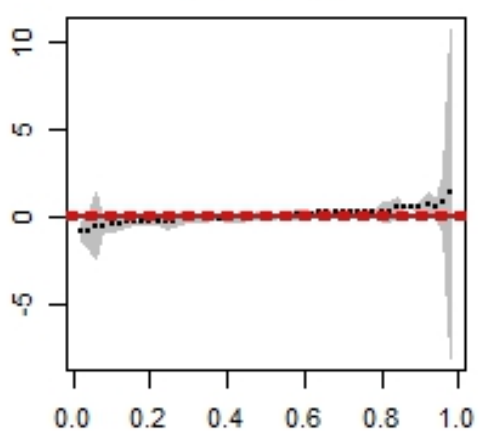

Nationally.Oldest

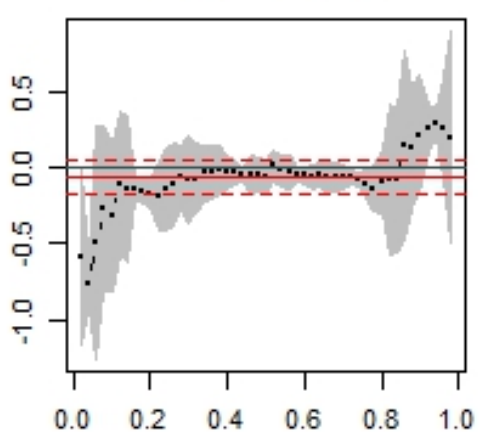

XZ1.Trade_Area.Oldest

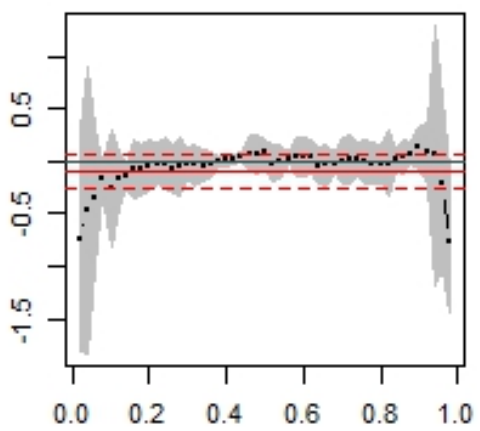

Z1.Trade_Area.Largest

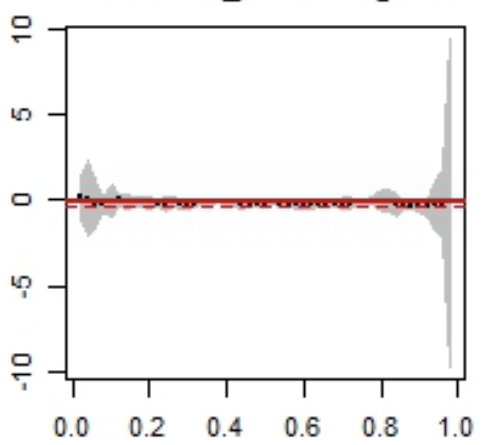

Nationally.Largest

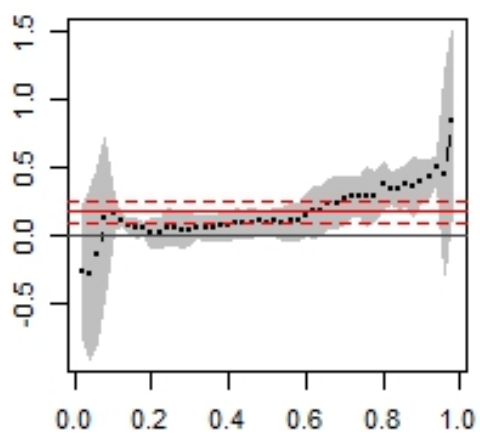

XZ1.Trade_Area.Largest

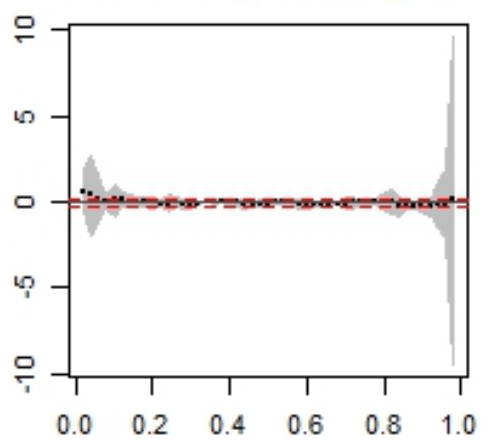

Z1.Trade_Area.Tallest

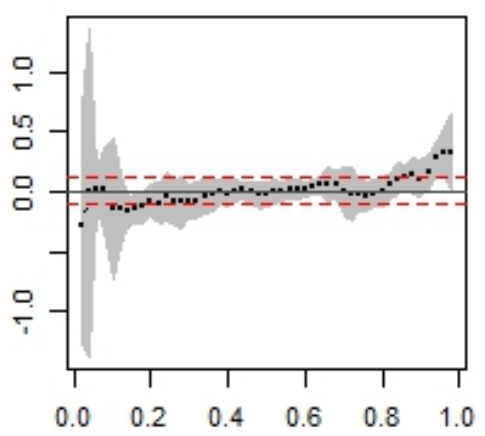

Nationally.Tallest

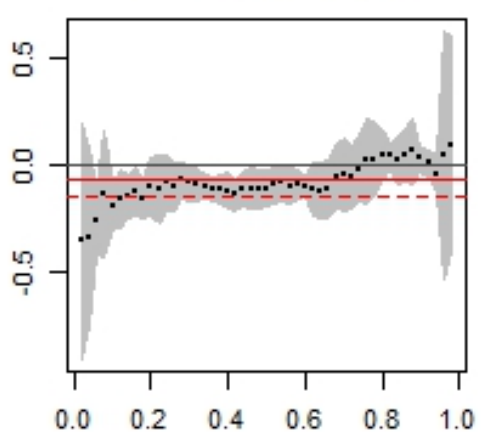

XZ1.Trade_Area.Tallest

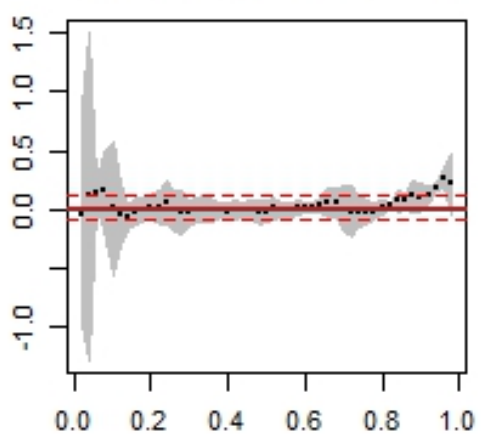

Fig 5 Enhanced Quantile Regression Coefficient Estimates

Notes: Notes: This quantile regression plot depicts how the extreme attributes (specified plot titles) are differently associated with the dependent variable $(\epsilon)$ across its quantiles. $\in$ is the residual extracted from a baseline hedonic model of the natural log of sale price. The analysis is applied to hotel sales in the U.S. from 1991 to 2013 for a sample of nearly 4,800 hotel transactions. Dashed horizontal lines are the confidence interval for the baseline hedonic model applied to the same data. The dotted curve is the coefficient estimate from the quantile regression. Its confidence intervals are depicted by the grey band. Trade area refers to the 20-minutes driving distance radius surrounding a subject hotel. Nationally oldest, largest and tallest categories are based on the top $1 \%$ hotels based on the hotel age, number of rooms and number of floors respectively. Z1 prefix signifies that the extreme attributes are also characterized by being at least one standard deviation higher than the trade-area mean. XZ1 prefixes signify that the specified extreme attributes (of another hotel in the neighborhood relative to the subject hotel) exceeded one standarddeviation from the mean of the trade-area hotels. 
Table 9 Summary of Quantile Regressions

\begin{tabular}{|c|c|c|c|c|c|}
\hline Basis of Extremes & Attribute & Conspicuity status & Discount Quantiles & Premium Quantiles & F-Stat \\
\hline \multirow[t]{8}{*}{ Trade Area } & \multirow[t]{4}{*}{ Largest } & All & Negative & Negative & $8.1^{* * *}$ \\
\hline & & $\mathrm{Z}=1$ & Negative & Negative & $8.0 * * *$ \\
\hline & & $\mathrm{Z}=2$ & Negative & Insignificant & $4.0 * *$ \\
\hline & & $\mathrm{Z}=3$ & Negative & Negative & 0.0 \\
\hline & \multirow[t]{4}{*}{ Tallest } & All & Negative & Positive & 0.4 \\
\hline & & $\mathrm{Z}=1$ & Negative & Positive & 0.7 \\
\hline & & $Z=2$ & Negative & Insignificant & 1.6 \\
\hline & & $\mathrm{Z}=3$ & Negative & Insignificant & $3.5^{*}$ \\
\hline \multirow[t]{3}{*}{ Nationally } & Oldest & Top 1\% & Negative & Positive & 0.8 to 0.9 \\
\hline & Largest & Top 1\% & Positive & Positive & 9.0 to 11.0 \\
\hline & Tallest & Top 1\% & Negative & Positive & 1.9 to 2.6 \\
\hline \multirow{9}{*}{$\begin{array}{l}\text { Externality } \\
\text { (w/in trade area) }\end{array}$} & \multirow[t]{3}{*}{ Oldest } & $\mathrm{Z}=1$ & Negative & Insignificant & 1.7 \\
\hline & & $Z=2$ & Negative & Positive & 0.1 \\
\hline & & $\mathrm{Z}=3$ & Insignificant & Insignificant & 0.0 \\
\hline & \multirow[t]{3}{*}{ Largest } & $\mathrm{Z}=1$ & Insignificant & Insignificant & 0.1 \\
\hline & & $\mathrm{Z}=2$ & Insignificant & Positive & 1.2 \\
\hline & & $\mathrm{Z}=3$ & Insignificant & Positive & 0.5 \\
\hline & \multirow[t]{3}{*}{ Tallest } & $\mathrm{Z}=1$ & Insignificant & Positive & 0.1 \\
\hline & & $Z=2$ & Positive & Negative & 0.4 \\
\hline & & $\mathrm{Z}=3$ & Insignificant & Insignificant & 0.0 \\
\hline
\end{tabular}

Notes: This table reports how extreme asset attributes are associated with marginal asset values differently across the discount and premium quantiles from a secondstage quantile regression. These two quantile types are determined from unexplained price variations (residuals) from the first-stage (baseline) hedonic model. Quantiles above the median of the first-stage residuals are considered "premium". Coefficients are extracted from the second-stage quantile regressions conducted on the residuals (tau=2\% to tau $=100 \%$ ) from the baseline model. The sign of the coefficients of various extreme attributes are reported if they are found to be statistically significant (at 5\% level) in some quantiles. "Trade area” is defined by a polygon within 20 minutes driving distance of a subject hotel. "Trade Area" and "Nationally" extreme attributes are the subject asset's own attributes. "Externality" attributes refer to neighboring assets within the trade area with the extreme attributes, if the subject asset itself is not extreme. Z refers to the Z-statistics of the extreme attribute within the trade area. For example, Externality $>>$ Tallest $>>Z=1$ signifies an asset in the neighborhood (other than the subject asset) which is the tallest and the height of the asset is at least one standard deviation higher than the mean of the subject asset's trade area. The last column reports the F-statistics for the difference of the coefficient across different quantiles examined in the model. $* * *, * *$ and $*$ denote statistical significance at $1 \%, 5 \%$ and $10 \%$ levels, respectively. 
Tallest

While the size of an asset is directly associated with demand and supply fundamentals, the same cannot be said for the height. Arguably, the desire to invest in extremely tall buildings is often driven by ego, status (Barr 2010a; Barr 2010b) or symbolism (Helsley and Strange, 2008). This is particularly true for assets being traded in the premium segment. Our empirical findings support this notion. The premium segments assign additional value for being the tallest, both at the local and national levels. However, buyers in the discount segments who are less sensitive to deriving the status from extreme heights assign an additional atypicality discount to being the tallest either at national or local levels, consistent with Helsley and Strange (2008). Our analysis suggests a separating equilibrium with respect to the tallest status in assets across the premium and discount segments.

\section{Oldest}

Our baseline models suggest a complex association between an asset's age and price because of the vintage effect. By definition, the nationally oldest assets (in the $99^{\text {th }}$ percentile) are 112 years or older. While these assets may offer a history and strong vintage effect, they may also imply high capital expenditure and ongoing expenses on energy and utilities. Therefore, being nationally the oldest is valued only in the premium segments. Whereas being an extremely old asset is significantly detrimental to prices in the discount segment.

\section{Externality of Assets with Extreme Attributes}

The oldest asset in the vicinity may benefit from its increased status and recognition. However, this would come at the cost of the demand for neighboring assets. Therefore, prices of the discount assets, in particular, are negatively associated with the presence of another asset in the locality which enjoys a bump in status for being the oldest. Similar behavior has been reported among residential consumers (Leguizamon 2010). However, the surrounding assets may enjoy a positive externality from the "historic" nature of a neighboring asset if it is substantially old. Therefore, the negative externality of the oldest asset diminishes gradually with its increasing age-conspicuity (i.e. $\mathrm{Z}$ value). Conversely, premium assets in a locality tend to build economy of agglomeration for a certain segment of consumers and may improve each others' business during times of peak demand. If they benefit from the increased recognition of surrounding assets, they exhibit a "bandwagon" (Corneo and Jeanne 1997) effect.

We detect some evidence that the assets in the discount segment benefit from the presence of the tallest asset in their locality. However, unlike the size and age which are directly associated with the cash flow performance of an asset (through higher revenue potential or higher capital expenditure respectively), the extreme building height is primarily a matter of status. Premium investors exhibit a "snobbery effect" (Corneo and Jeanne 1997) in presence of another asset in the neighborhood which conspicuously boasts of the "tallest" status. The presence of a locally oldest or tallest asset in the neighborhood also separates the equilibrium across the discount and premium segments, as the values are associated differently (positive versus negative, respectively).

\section{Conclusions}

The motivation for a purchase differs across consumption and investment decisions. While conspicuous consumption at the individual or household level has received a great deal of attention 
in the extant real estate literature, our knowledge of conspicuous investment is limited. This study examines investment in conspicuous assets among commercial real estate investors, with a particular focus on the price impact of extreme asset attributes - such as the status of being the oldest, largest or the tallest.

In this study, we reconcile previous findings and identify the contexts in which an asset's extreme attributes can be value enhancing or value diminishing. We examine the marginal price impact of extreme attributes (size, height, age) measured both at local and national levels. Although the baseline hedonic model we employ prices most of these attributes, it is agnostic in regards to the relative attribute measurements - which may lead to significant price impacts. We conduct several model mis-specification tests and establish that the baseline hedonic approach that is often used in the extant literature is prone to omitted variable bias and the resulting models are insufficiently specified. We argue that extreme asset attributes and their externality are among the omitted variables.

To overcome this issue we run a series of quantile regressions that examine the unexplained price component in the baseline model. We find that being locally the largest is penalized across both the premium and discount hotel segments - although the positive impact of being the nationally largest substantially offsets the negative impact. This suggests that locally largest assets, unless also being among the nationally largest, are considered atypical and trade at a discount. Further, we detect that locally largest assets in the neighborhoods create positive asset price externalities in the premium hotel segment although the discount hotel segment is unaffected by them.

We detect separating equilibrium with respect to extreme asset age and height. Asset prices in the discount segment are negatively affected if an asset is among the oldest nationally or the tallest either locally or nationally since these extreme attributes may affect the cash flows negatively. However, the same extreme attributes are associated with a significantly higher price in the premium segment where the negative cash flow effect is substantially offset by the positive status effect. The externality of an asset which is locally the oldest or tallest is mostly insignificant in the discount segment. However, premium segments assign additional value if situated close to an asset which is conspicuously the oldest.

Our study suggests that pricing models for commercial real estate can be enhanced by incorporating the extreme asset characteristics. The measurement of such externalities does not require additional data collection; yet explains asymmetric investor behavior across assets and markets. In this study we limit our focus to asset-level price performance. That purchasers of premium assets pay a premium leads to inconclusive inferences about the prudence of such

purchases unless it can be shown that assets lead to superior holding-period returns. We leave this examination for future research.

\section{References}

Abadie, A., \& Dermisi, S. (2008). Is terrorism eroding agglomeration economies in Central Business Districts? Lessons from the office real estate market in downtown Chicago. Journal of Urban Economics, 64(2), 451-463. http://doi.org/10.1016/j.jue.2008.04.002 
Bagwell, L. S., \& Bernheim, B. D. (1996). Veblen effects in a theory of conspicuous consumption. The American Economic Review, 86(3), 349-373. http://doi.org/10.1126/science.151.3712.867-a

Blal, I. \& Graf, N.S. (2013). The discount effect of non-normative physical characteristics on the price of lodging properties. International Journal of Hospitality Management, 34, 413-422.

Barr, J. (2010a). Skyscraper Height. The Journal of Real Estate Finance and Economics, 45(3), 723-753. http://doi.org/10.1007/s11146-010-9274-z

Barr, J. (2010b). Skyscrapers and the skyline: Manhattan, 1895-2004. Real Estate Economics, 38(3), 567-597. http://doi.org/10.1111/j.1540-6229.2010.00277.x

Brennan, T. P., Cannaday, R. E., \& Colwell, P. F. (1984). Office rent in the chicago CBD. Real Estate Economics, 12(3), 243-260. Retrieved from http://ideas.repec.org/a/bla/reesec/v12y1984i3p243-260.html

Campbell, J. D. (2014). Localized price promotions as a quality signal in a publicly observable network. Quantitative Marketing and Economics, 13(1), 27-57. http://doi.org/10.1007/s11129-014-9153-7

Capozza, D. R., Israelsen, R. D., \& Thomson, T. A. (2005). Appraisal, agency and atypicality: Evidence from manufactured homes. Real Estate Economics, 33(3), 509-537. Retrieved from http://www.scopus.com/scopus/inward/record.url?eid=2-s2.017544363804\&partnerID=40

Corgel, J. B., \& deRoos, J. A. (1994). Buying high and selling low in the lodging-property market. Cornell Hotel and Restaurant Administration Quarterly, 35(6), 33-38. http://doi.org/10.1177/001088049403500610

Corgel, J. B., Liu, C., \& White, R. M. (2015). Determinants of hotel property prices. The Journal of Real Estate Finance and Economics. http://doi.org/10.1007/s11146-015-9494-3

Corneo, G., \& Jeanne, O. (1997). Conspicuous consumption, snobbism and conformism. Journal of Public Economics, 66(1), 55-71. http://doi.org/10.1016/S0047-2727(97)00016-9

Das, P. (2015). Revisiting the hotel capitalization rate. International Journal of Hospitality Management, 46, 151-160. http://doi.org/10.1016/j.ijhm.2015.02.003

Das, P., \& Wiley, J. a. (2014). Determinants of premia for energy-efficient design in the office market. Journal of Property Research, 31(1), 64-86. http://doi.org/10.1080/09599916.2013.788543

Eichholtz, P., Kok, N., \& Quigley, J. M. (2010). Doing well by doing good ? Green office buildings. The American Economic Reviews, 100(5), 2492-2509.

Ellingsen, T., \& Johannesson, M. (2008). Pride and prejudice: The human side of incentive theory. American Economic Review, 98(3), 990-1008. http://doi.org/10.1257/aer.98.3.990

Esrig, D., Hudgins, M. C., \& Cerreta, L. (2011). Revisiting the impact of large assets on real 
estate portfolio returns. The Journal of Portfolio Management, 35(5), 125-136. http://doi.org/10.3905/jpm.2011.35.5.125

Gat, D. (1998). Toward a theory of the intraurban market for hotel services. Journal of Real Estate Finance and Economics, 211, 199-212.

Ghysels, E., Plazzi, A., \& Valkanov, R. (2007). Valuation in US commercial real estate. European Financial Management, 13(3), 472-497. http://doi.org/10.1111/j.1468036X.2007.00369.X

Gifford, R. (2007). The consequences of living in high-rise buildings. Architectural Science Review, 50(1), 2. http://doi.org/10.3763/asre.2007.5002

Harrington, Jr, J. E. (2009). Games, Strategies, and Decision Making (2nd ed.). New York: Worth.

Heffetz, O. (2011). A test of conspicuous consumption: visibility and income elasticities. Review of Economics and Statistics, 93(4), 1101-1117. http://doi.org/10.1162/REST_a_00116

Helsley, R. W., \& Strange, W. C. (2008). A game-theoretic analysis of skyscrapers. Journal of Urban Economics, 64(1), 49-64. http://doi.org/10.1016/j.jue.2007.08.004

Hung, W. T., Shang, J. K., \& Wang, F. C. (2010). Pricing determinants in the hotel industry: Quantile regression analysis. International Journal of Hospitality Management, 29(3), 378384. http://doi.org/10.1016/j.ijhm.2009.09.001

Jeary, A. P., Morris, R. G., \& Tomlinson, R. W. (1988). Perception of vibration - tests in a tall building. Journal of Wind Engineering and Industrial Aerodynamics, 29, 361-370. http://doi.org/10.1016/0167-6105(88)90132-8

Kallberg, J. G., Liu, C. H., \& Greig, D. W. (1996). The role of real estate in the portfolio allocation process. Real Estate Economics, 24(3), 359-377. http://doi.org/10.1111/15406229.00695

Kimes, S. E., \& Fitzsimmons, J. a. (1990). Selecting profitable hotel sites at La Quinta Motor Inns. Interfaces, 20(2), 12-20. http://doi.org/10.1287/inte.20.2.12

Lee, K. O., \& Mori, M. (2016). Do Conspicuous Consumers Pay Higher Housing Premiums? Spatial and Temporal Variation in the United States. Real Estate Economics, 44(3), 726763.

Lee, S. K., \& Jang, S. (2012). Premium or discount in hotel room rates? The dual effects of a central downtown location. Cornell Hospitality Quarterly, 53(2), 165-173. http://doi.org/10.1177/1938965512441056

Leguizamon, S. (2010). The influence of reference group house size on house price. Real Estate Economics, 38(3), 507-527. http://doi.org/10.1111/j.1540-6229.2010.00275.x

Lin, Z., Rosenblatt, E., \& Yao, V. W. (2009). Spillover effects of foreclosures on neighborhood property values. The Journal of Real Estate Finance and Economics, 38(4), 387-407. 
http://doi.org/10.1007/s11146-007-9093-z

Lizieri, C., \& Pain, K. (2013). International office investment in global cities: The production of financial space and systemic risk. Regional Studies, 48(3), 439-455. http://doi.org/10.1080/00343404.2012.753434

Lockwood, L. J., \& Rutherford, R. C. (1996). Determinants of industrial property value. Real Estate Economics, 24(2), 257-272.

McDonald, J., \& Dermisi, S. (2008). Capitalization rates, discount rates, and net operating income: The case of downtown Chicago office buildings. Journal of Real Estate Portfolio Management, 14(4), 363-374.

McGrath, K. M. (2013). The effects of eco-certification on office properties: a cap rates-based analysis. Journal of Property Research, 30(4), 345-365. http://doi.org/10.1080/09599916.2012.762034

McMillen, D. P. (2008). Changes in the distribution of house prices over time: Structural characteristics, neighborhood, or coefficients? Journal of Urban Economics, 64(3), 573589. http://doi.org/10.1016/j.jue.2008.06.002

Nesbitt, S., \& Phen. (1995). Buy high, sell low: Timing errors in mutual fund allocation. Journal of Portfolio Management, 22(1), 57-60.

Pai, A., \& Geltner, D. (2007). Stocks are from Mars, real estate is from Venus. The Journal of Portfolio Management, 33(5), 134-144. http://doi.org/10.3905/jpm.2007.698912

Pauls, J. (1987). Calculating evacuation times for tall buildings. Fire Safety Journal, 12(3), 213236. http://doi.org/10.1016/0379-7112(87)90007-5

Peng, L. (2013). Finding cap rates: a property level analysis of commercial real estate pricing. University of Colorado at Boulder Leeds School of Business. Retrieved from http://www.reri.org

Plazzi, A., Torous, W., \& Valkanov, R. (2011). Exploiting property characteristics in commercial real estate portfolio allocation. The Journal of Portfolio Management, 37(5), 39-50. http://doi.org/10.3905/jpm.2011.37.5.039

Robinson, S., Singh, A. J., \& Das, P. (2016). Financial impact of LEED and Energy Star certifications on hotel revenues. The Journal of Hospitality Financial Management, 24(2), 110-126. http://doi.org/10.1080/10913211.2016.1236567

Rosen, S. (1974). Hedonic prices and implicit markets: product differentiation in pure competition. Journal of Political Economy, 82(1), 34. http://doi.org/10.1086/260169

Rushmore, S. (2012). Hotel Market Analysis and Valuation International Issues and Software Applications. Appraisal Institute.

Slade, B. (2000). Office rent determinants during market decline and recovery. Journal of Real Estate Research, 20(3), 357-380. 
Smith, B. C. (2004). Economic depreciation of residential real estate: microlevel space and time analysis. Real Estate Economics, 32(1), 161-180. http://doi.org/10.1111/j.10808620.2004.00087.x

Thrall, G. I. (2002). Business Geography and New Real Estate Market Analysis (Spatial Information Systems). Oxford University Press.

Titman, S., \& Twite, G. (2013). Urban density, law and the duration of real estate leases. Journal of Urban Economics, 74, 99-112. http://doi.org/10.1016/j.jue.2012.10.003

Utts, J. M. (1982). The rainbow test for lack of fit in regression. Communications in Statistics Theory and Methods, 11(24), 2801-2815. http://doi.org/10.1080/03610928208828423

Zahirovich-Herbert, V., \& Chatterjee, S. (2011). What is the value of a name? Conspicuous consumption and house prices. Journal of Real Estate Research, 33(1), 105-125.

Ziering, B., \& McIntosh, W. (1999). Property size and risk: Why bigger is not always better. Journal of Real Estate Portfolio Management, 5(2), 105-112.

Zietz, J., Zietz, E. N., \& Sirmans, G. S. (2008). Determinants of house prices: A quantile regression approach. Journal of Real Estate Finance and Economics, 37(4), 317-333. http://doi.org/10.1007/s11146-007-9053-7

\section{Appendix}

Appendix Table 1 Top and Bottom submarkets for hotel pricing

\begin{tabular}{ll}
\hline Top-10 & Premium or Discount \\
\hline Times Square Area, NY & $2.028^{* * *}(0.246)$ \\
Lower Manhattan, NY & $1.821^{* * *}(0.232)$ \\
New York City Uptown/Midtown East, NY & $1.714^{* * *}(0.262)$ \\
Hollywood/Beverly Hills, CA & $1.710^{* * *}(0.253)$ \\
Kauai, HI & $1.610^{* * *}(0.377)$ \\
San Jose Northwest/Palo Alto, CA & $1.548^{* * *}(0.291)$ \\
Santa Monica/Marina Del Rey, CA & $1.513^{* * *}(0.382)$ \\
Key West, FL & $1.478^{* * *}(0.266)$ \\
Santa Barbara/Santa Maria, CA & $1.441^{* * *}(0.244)$ \\
Arlington, VA & $1.378^{* * *}(0.308)$ \\
\hline
\end{tabular}

\begin{tabular}{ll}
\hline Bottom-10 & $-1.336^{* * *}(0.223)$ \\
\hline Hartford CBD/South, CT & $-1.354^{* * *}(0.220)$ \\
Birmingham CBD/Airport, AL & $-1.373^{* * *}(0.232)$ \\
Columbus CBD/Ohio State Univ, OH & $-1.389^{* * *}(0.227)$
\end{tabular}


Albuquerque CBD/Airport/South, NM

$-1.516^{* * *}(0.311)$

Charlotte CBD/Airport, SC

$-1.559^{* * *}(0.154)$

Des Moines CBD/North, IA

$-1.605^{* * *}(0.213)$

Fort Worth CBD/I-820 West, TX

$-1.607^{* * *}(0.274)$

Cleveland CBD/Independence, OH

$-1.660^{* * *}(0.251)$

Tulsa CBD/Airport, OK

$-2.112^{* * *}(0.248)$

Notes: This table provides the coefficients of the dummy variables for selected (top and bottom) metropolitan areas from the baseline hedonic model where natural log of the sale price is the dependent variable. Therefore, exponent of the dummy variable is the multiplicative premium / discount. The baseline hedonic model controls for asset characteristics, location characteristics and the market cycle.

Appendix Table 2 Distribution of Extreme Attributes Across Premium and Discount Assets

\begin{tabular}{lrrrrrr}
\hline \multicolumn{7}{c}{ Subsamples based on the Residuals of the Baseline Model } \\
\hline & $\begin{array}{c}\text { 95th and } \\
\text { Above }\end{array}$ & $\begin{array}{c}\text { 90th and } \\
\text { Above }\end{array}$ & $\begin{array}{c}\text { 75th and } \\
\text { Above }\end{array}$ & $\begin{array}{c}\text { 25th and } \\
\text { Below }\end{array}$ & $\begin{array}{c}\text { 10th and } \\
\text { Below }\end{array}$ & $\begin{array}{c}\text { 5th and } \\
\text { Below }\end{array}$ \\
\hline Nationally Oldest & $2.5 \%$ & $1.7 \%$ & $0.9 \%$ & $1.3 \%$ & $1.7 \%$ & $2.5 \%$ \\
Nationally Largest & $8.8 \%$ & $5.4 \%$ & $3.2 \%$ & $1.9 \%$ & $2.5 \%$ & $2.9 \%$ \\
Nationally Tallest & $5.8 \%$ & $4.6 \%$ & $2.8 \%$ & $2.9 \%$ & $4.0 \%$ & $3.8 \%$ \\
Trade-Area Largest & $3.8 \%$ & $3.5 \%$ & $3.7 \%$ & $5.3 \%$ & $6.7 \%$ & $7.1 \%$ \\
Trade-Area Tallest & $5.8 \%$ & $5.0 \%$ & $5.1 \%$ & $6.4 \%$ & $8.1 \%$ & $8.3 \%$ \\
\hline
\end{tabular}

Notes: Trade-area of a hotel is defined as a polygon within 20 minutes driving distance. Nationally oldest, largest and tallest categories are based on the top $1 \%$ hotels based on the hotel age, number of rooms and number of floors respectively. 
(Intercept)

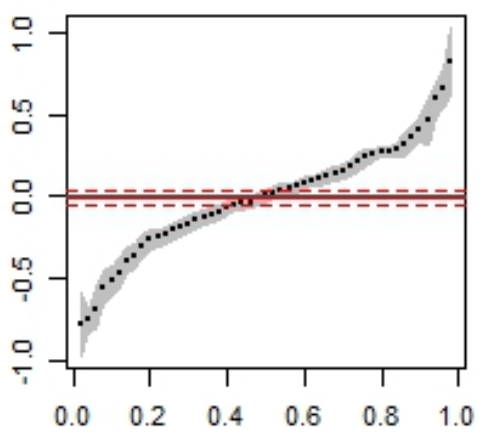

Nationally.Oldest

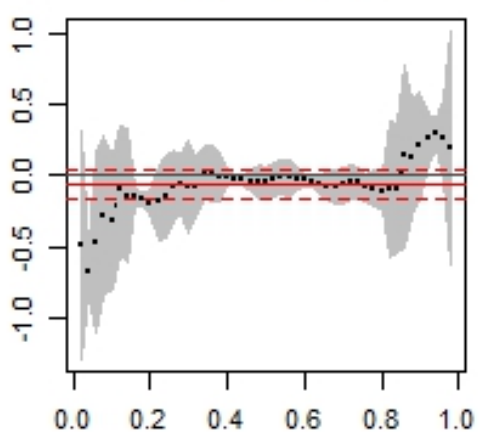

XZ2.Trade_Area.Oldest

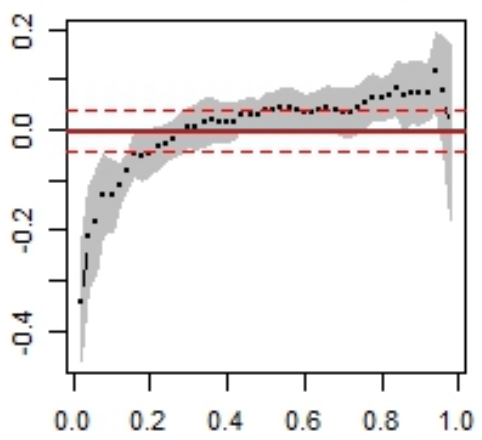

Z2.Trade_Area.Largest

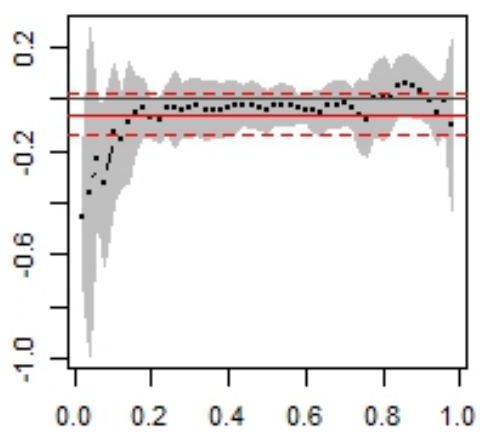

Nationally.Largest

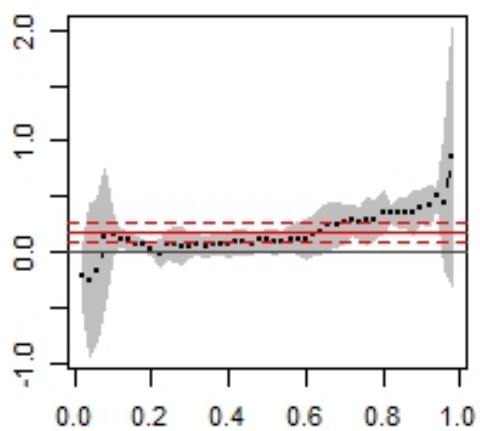

XZ2.Trade_Area.Largest

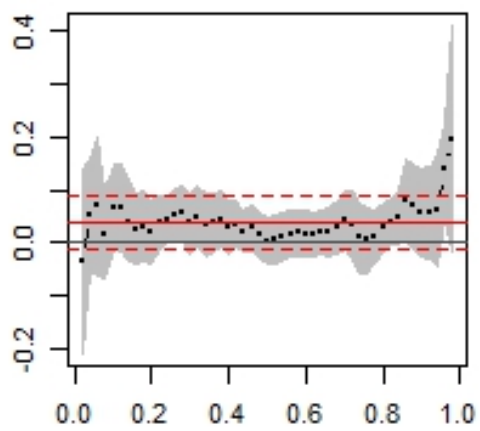

Z2.Trade_Area.Tallest

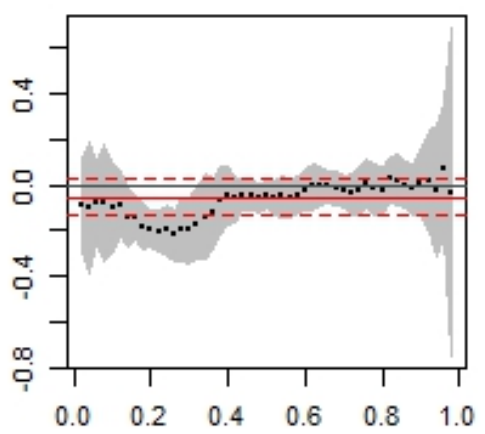

Nationally.Tallest

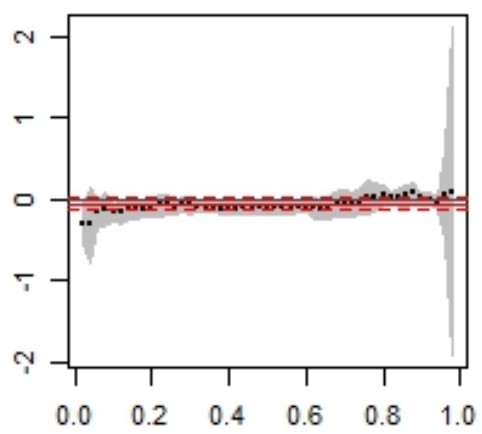

XZ2.Trade_Area.Tallest

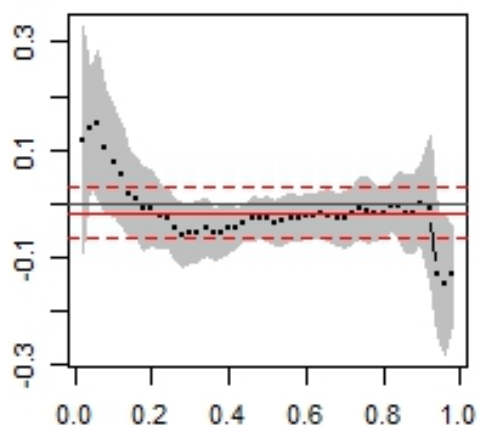

Appendix Fig 1 Enhanced Quantile Regression Estimates with the conspicuity level of Z=2

Notes: Notes: This quantile regression plot depicts how the extreme attributes (specified plot titles) are differently associated with the dependent variable $(\epsilon)$ across its quantiles. $\in$ is the residual extracted from a baseline hedonic model of the natural log of sale price. The analysis is applied to hotel sales in the U.S. from 1991 to 2013 for a sample of nearly 4,800 hotel transactions. Dashed horizontal lines are the confidence interval for the baseline hedonic model applied to the same data. The dotted curve is the coefficient estimate from the quantile regression. Its confidence intervals are depicted by the grey band. Trade area refers to the 20-minutes driving distance radius surrounding a subject hotel. Nationally oldest, largest and tallest categories are based on the top $1 \%$ hotels based on the hotel age, number of rooms and number of floors respectively. Z2 prefix signifies that the extreme attributes are also characterized by being at least two standard deviations higher than the trade-area mean. XZ2 prefix signifies that the specified extreme attributes (of another hotel in the neighborhood relative to the subject hotel) exceeded two standarddeviations from the mean of the trade-area hotels. 

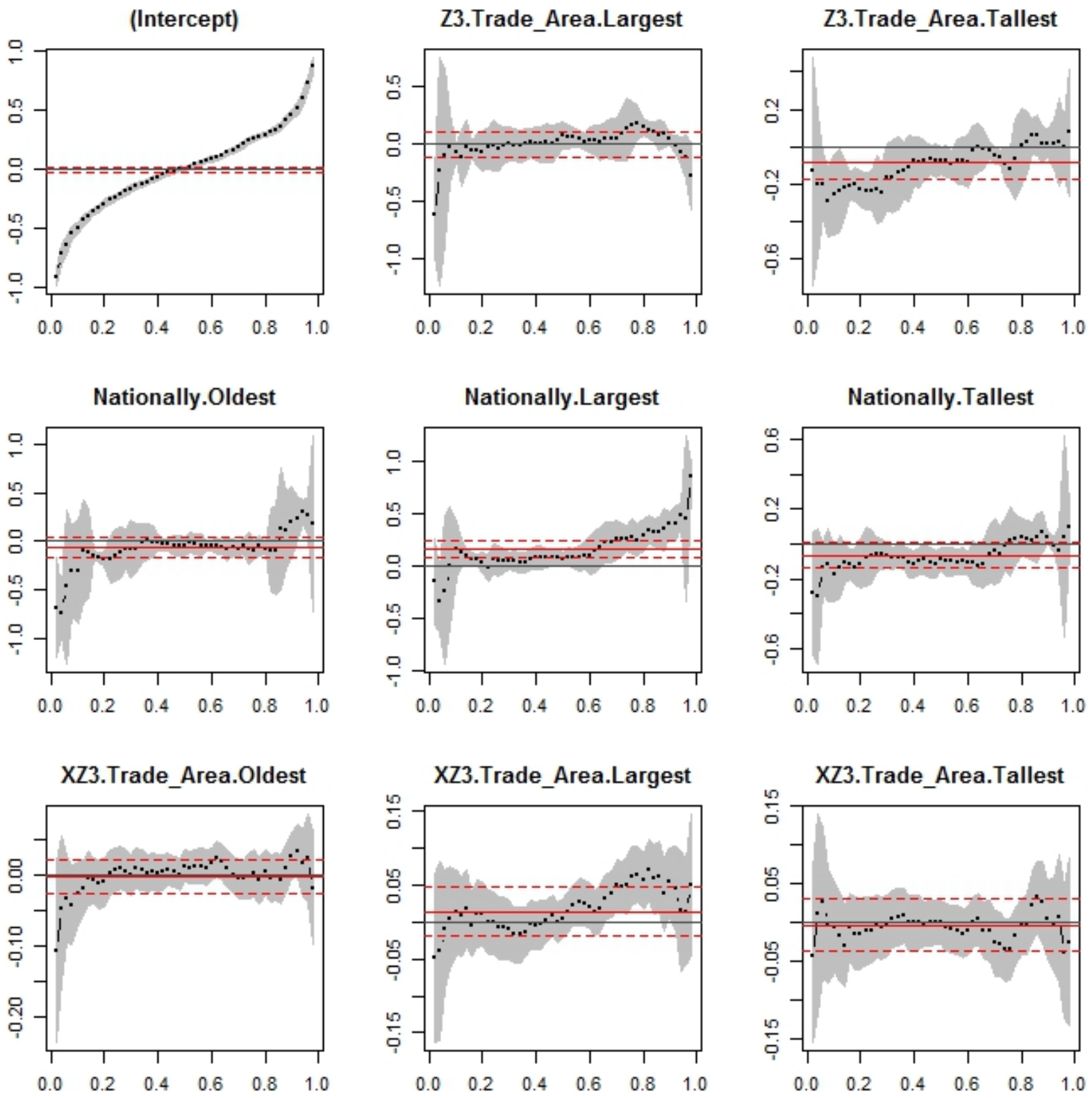

Appendix Fig 2 Enhanced Quantile Regression Estimates with the conspicuity level of Z=3

Notes: This quantile regression plot depicts how the extreme attributes (specified plot titles) are differently associated with the dependent variable $(\epsilon)$ across its quantiles. $\epsilon$ is the residual extracted from a baseline hedonic model of the natural log of sale price. The analysis is applied to hotel sales in the U.S. from 1991 to 2013 for a sample of nearly 4,800 hotel transactions. Dashed horizontal lines are the confidence interval for the baseline hedonic model applied to the same data. The dotted curve is the coefficient estimate from the quantile regression. Its confidence intervals are depicted by the grey band. Trade area refers to the 20-minutes driving distance radius surrounding a subject hotel. Nationally oldest, largest and tallest categories are based on the top $1 \%$ hotels based on the hotel age, number of rooms and number of floors respectively. Z3 prefix signifies that the extreme attributes are also characterized by being at least three standard deviations higher than the trade-area mean. XZ3 prefix signifies that the specified extreme attributes (of another hotel in the neighborhood relative to the subject hotel) exceeded three standard-deviations from the mean of the trade-area hotels. 


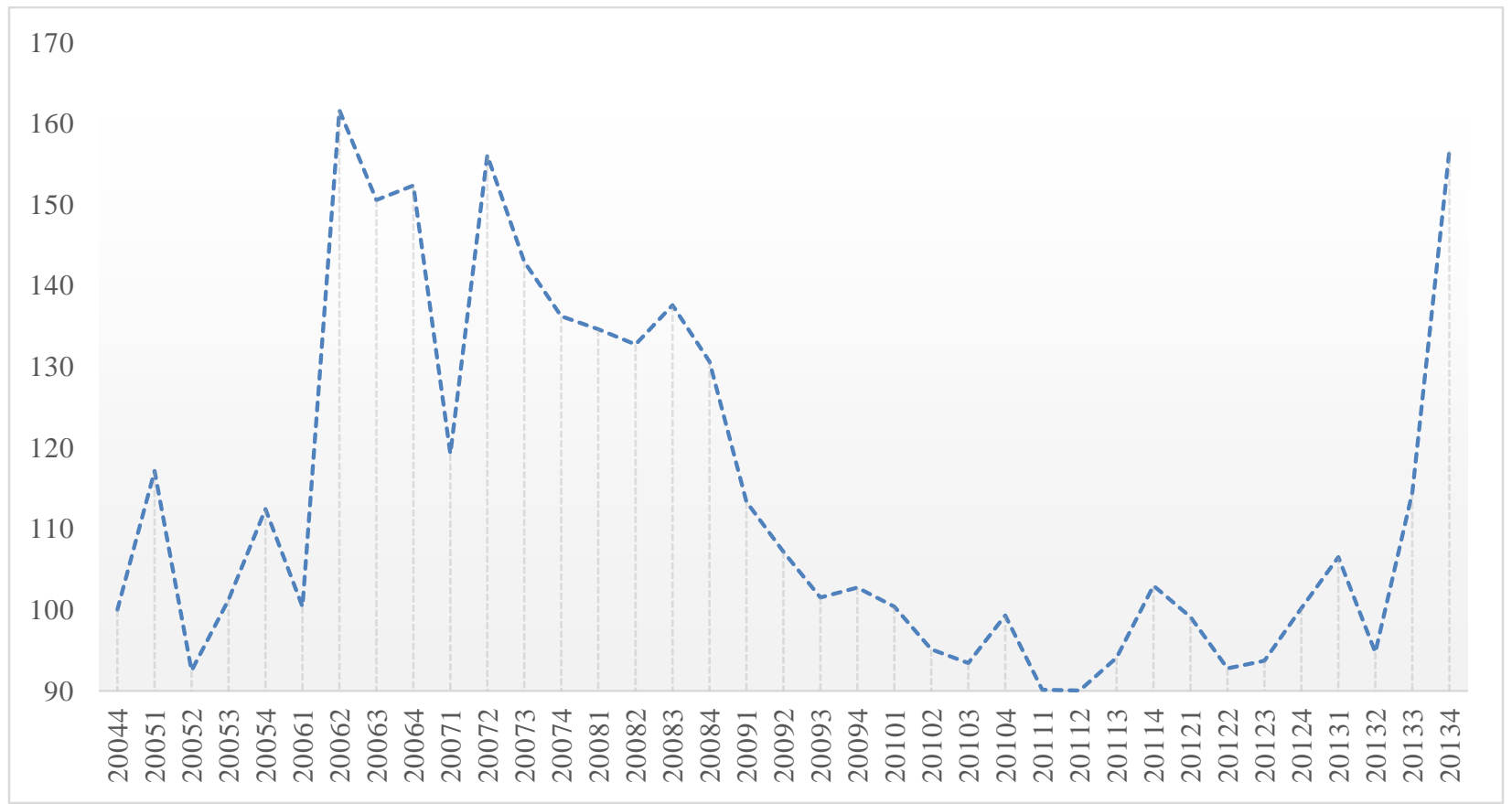

Appendix Figure 3 Quarterly Price Trend in the Baseline Model 